\title{
Nitrogen remobilisation facilitates adventitious root formation on reversible dark-induced carbohydrate depletion in Petunia hybrida
}

\author{
Siegfried Zerche ${ }^{1 *}$, Klaus-Thomas Haensch², Uwe Druege ${ }^{2}$ and Mohammad-Reza Hajirezaei ${ }^{3}$
}

\begin{abstract}
Background: Adventitious root (AR) formation in axillary shoot tip cuttings is a crucial physiological process for ornamental propagation that is utilised in global production chains for young plants. In this process, the nitrogen and carbohydrate metabolisms of a cutting are regulated by its total nitrogen content $\left(N_{t}\right)$, dark exposure during transport and irradiance levels at distinct production sites and phases through a specific plasticity to readjust metabolite pools. Here, we examined how elevated $N_{t}$ contents with a combined dark exposure of cuttings influence their internal $\mathrm{N}$-pools including free amino acids and considered early anatomic events of AR formation as well as further root development in Petunia hybrida cuttings.
\end{abstract}

Results: Enhanced $\mathrm{N}_{\mathrm{t}}$ contents of unrooted cuttings resulted in elevated total free amino acid levels and in particular glutamate ( $\mathrm{glu}$ ) and glutamine ( $\mathrm{g} / \mathrm{n})$ in leaf and basal stem. N-allocation to mobile N-pools increased whereas the allocation to insoluble protein- $N$ declined. A dark exposure of cuttings conserved initial $N_{t}$ and nitrate- $N$, while it reduced insoluble protein- $\mathrm{N}$ and increased soluble protein, amino- and amide-N. The increase of amino acids mainly comprised asparagine (asn), aspartate (asp) and arginine (arg) in the leaves, with distinct tissue specific responses to an elevated $\mathrm{N}$ supply. Dark exposure induced an early transient rise of asp followed by a temporary increase of glu. A strong positive $\mathrm{N}$ effect of high $\mathrm{N}_{\mathrm{t}}$ contents of cuttings on AR formation after $384 \mathrm{~h}$ was observed. Root meristematic cells developed at $72 \mathrm{~h}$ with a negligible difference for two $N_{t}$ levels. After $168 \mathrm{~h}$, an enhanced $N_{t}$ accelerated AR formation and gave rise to first obvious fully developed roots while only meristems were formed with a low $N_{t}$. However, dark exposure for $168 \mathrm{~h}$ promoted AR formation particularly in cuttings with a low $\mathrm{N}_{t}$ to such an extent so that the benefit of the enhanced $N_{t}$ was almost compensated. Combined dark exposure and low $N_{t}$ of cuttings strongly reduced shoot growth during AR formation.

Conclusions: The results indicate that both enhanced $\mathrm{N}_{t}$ content and dark exposure of cuttings reinforced $\mathrm{N}$ signals and mobile $\mathrm{N}$ resources in the stem base facilitated by senescence-related proteolysis in leaves. Based on our results, a model of $\mathrm{N}$ mobilisation concomitant with carbohydrate depletion and its significance for AR formation is postulated.

Keywords: Root primordium, Meristem, Root elongation, Nitrogen deficiency, Dark response, Carbohydrate depletion, Amino acids, Adventitious root formation

\footnotetext{
* Correspondence: zerche@erfurt.igzev.de

${ }^{1}$ Department of Plant Nutrition, Leibniz Institute of Vegetable \& Ornamental

Crops (IGZ), Kuehnhaeuser Str. 101, 99090 Erfurt, Germany

Full list of author information is available at the end of the article
} 


\section{Background}

Adventitious root (AR) formation with high economic significance in horticulture, agriculture and forestry is a complex physiological process. The ornamental plant propagation relies on globalised chains for young plant production via rooting of cuttings ensuring an effective utilization of beneficial external and internal factors. The whole process includes three phases, axillary bud and shoot growth on donor plants (providing recurrent excision of mature shoot tips - i.e. cuttings), subsequent logistics (i.e. transport, storage) of cuttings and insertion of the cuttings into rooting media. During this process strong transcriptomic and metabolic changes occur with high importance of nitrogen availability, dark exposure and various irradiance levels. Thus, reciprocal regulations force adaptations in nitrogen and carbohydrate metabolism during phases of axillary bud and shoot growth, dark induced senescence of cuttings, stress recovery under diurnal light and AR formation in cuttings. It has already been shown that the level of nitrogen assimilation by donor plants changes nitrogen fluxes and rebalances the pools of carbohydrates and amino acids [1, 2]. Moreover, degradation and re-synthesis of proteins enable survival of rootless cuttings and are required for the regeneration of the missing root organs. Since AR formation relies on selective proteolysis and re-synthesis of proteins, the total nitrogen stock in the cuttings constitutes a key limiting factor $[3,4]$. Interestingly, there are similarities and differences between AR formation and lateral roots $[5,6]$ especially for nitrogen deficiency and ethylene signalling and synthesis in planta. $\mathrm{N}$ deficiency stimulates lateral roots of sessile plants having already their intact root system. Then lateral root formation starts with highly cell-specific responses to external nitrogen signals that are directed towards nutrient-rich soil patches to ensure nutrient acquisition [7]. In contrast, excised axillary shoot tips (i.e. cuttings) such as petunia cuttings experience wounding and isolation and thus solely rely on shoot-born signals with specific transcriptome and metabolome responses [8-10]. When the vascular continuum collapses, auxin accumulates and induces AR formation in stem base tissue [11]. Primary auxin control of AR formation depends on secondary signals like nitric oxide, polyamines and ethylene $[6,12,13]$. Recently, an aminotransferase protein was reported to coordinate the biosynthesis of the hormones ethylene and auxin [14]. Further, auxin triggers the activation of a plant target of rapamicin complex that is expressed in primary meristems and integrates auxin and nutrient signalling by regulated protein translations [15]. Thus, nitrogen resources are pivotal for protein synthesis in the stem base of cuttings, wherein the predominant amino acids comprise glutamine (gln), glutamate (glu), asparagine (asn) and aspartate (asp) [8, 16]. Carbohydrate reserves and nitric oxide (NO) enhance resilience of plant tissues and survival of dark senescence [17-19]. As AR formation depends on protein re-synthesis $[3,4]$ from mobile or recycled nitrogen reserves such as asn $[20,21]$ these could be limiting in case of $\mathrm{N}$ deficiency and result in an accelerated leaf senescence [22, 23] differing from lateral roots formation, in this respect [24, 25]. So far nitrogen and carbohydrate limitations of AR formation have been shown in Pelargonium, Chrysanthemum, Poinsettia and Rosa [17, 26-28]. Enhanced AR formation at high nitrogen contents may be related to an increased basipetal transport of carbohydrates [26] and nitrogenous compounds [20] with limited knowledge of the causal mechanisms including transcriptome, hormone and metabolic adaptations. Using Petunia hybrida as a model plant three metabolic phases for AR formation were established [9] during which nitrogen supply was maintained at adequate levels. A dynamic depletion and replenishment of carbohydrates has been reported in course of dark exposure of the cuttings and their subsequent rooting under light with stimulating effect on root formation [29]. In addition, at adequate nitrogen levels a strong contribution of the polar auxin transport (PAT) to AR formation was shown by an early increase of indole-3-acetic acid (IAA) in Petunia [16]. Moreover, multiple transcriptome changes in auxin transport systems, auxin conjugation and auxin signal perception uncovered auxin as a key regulator of AR formation during sink establishment phase $[9,16,30,31]$. At the sink side amino acids and nitrogen pools provide important $\mathrm{N}$ resources to meet the new demand for protein resynthesis. In addition, variation in $\mathrm{N}$ resources may have an influence on auxin levels. It is supposed that prior to excision of cuttings various signalling hormones including cytokinin (CK) communicate the nitrogen availability from donor plant roots to axillary shoots [32] and that their activity can be related partially to glutamine metabolism [33]. CK's are considered as auxin antagonists and important negative regulators of AR formation [34] that would counteract auxin distribution via down-regulation of PIN activity [35]. In contrast, CK's are also considered as important signals for dedifferentiation processes during early induction of ARs [4] and are required for fine tuning of the auxin transport and biosynthesis during the formation of the quiescent centre in the adventitious root apex [36]. In this regard, shoot levels of both CK's and gibberellins decline with an interrupted nitrogen supply to roots [37]. This complexity of functions of nitrogen metabolism interacting with plant hormone signalling might explain the lack of information on the influence of nitrogen nutrition of donor plants and dark exposure of cuttings on their nitrogen metabolism and AR formation. Therefore, the present study tested the hypothesis that enhanced $\mathrm{N}_{t}$ contents and dark exposure of cuttings influence their internal $\mathrm{N}$-pools including free amino acids and affect early events of AR formation and further root development in Petunia hybrida. 


\section{Results}

Anatomy of early events during AR formation at different nitrogen contents

The histological examinations revealed that first meristematic cells of developing root meristems, i.e. small cells with a dense cytoplasm and a large nucleus were visible at 72 hpin in stem base sections of cuttings with two different total nitrogen $\left(\mathrm{N}_{\mathrm{t}}\right)$ contents $\left(\mathrm{N}_{\mathrm{t}}\right.$-low: $2570 \mu \mathrm{mol} \mathrm{N} \mathrm{g}^{-1} \mathrm{DM}$, $\mathrm{N}_{\mathrm{t}}$-high: $3625 \mu \mathrm{mol} \mathrm{N} \mathrm{N}_{\mathrm{t}} \mathrm{g}^{-1} \mathrm{DM}$ ) (Fig. 1a, b). At this time the difference between the nitrogen contents was marginal but at 168 hpin there was a significant difference between the two $N_{t}$ levels. Whereas in the cuttings with the low $N_{t}$ level only meristems were formed as the most advanced structures (Fig. 1c), the treatment with the high $\mathrm{N}_{\mathrm{t}}$ level led to root formation with first cells characteristic for the elongation zone (Fig. 1d).

\section{Nitrogen pools in response to total $\mathrm{N}$-absorption by cuttings}

To characterise ranges of $\mathrm{N}_{\mathrm{t}}$ contents and fractionated pools of nitrogen (NF-pools) within excised cuttings, their growth (number and biomass) with distinct $\mathrm{N}$ dosage $\left(\mathrm{N}_{\mathrm{d}}\right)$ regimes to donor plants was monitored $\left(\mathrm{N}_{\mathrm{d}}\right.$-low, $\mathrm{N}_{\mathrm{d}}$-high, $\mathrm{N}_{\mathrm{d}}$-excess: $55 / 90 / 179 \mathrm{mg} \mathrm{N}$ plant $^{-1}$ week $^{-1}$ ) (Fig. 2a). The $\mathrm{N}_{\mathrm{t}}$ content of whole cuttings was determined on a dry mass (DM) basis (two sample sets, four biological replicates, $n=$ 24). The $\mathrm{N}_{\mathrm{d}}$-low, $\mathrm{N}_{\mathrm{d}}$-high and $\mathrm{N}_{\mathrm{d}}$-excess regimes produced $\mathrm{N}_{t}$ contents of cuttings of $3112 \pm 187,4034 \pm 107,5004 \pm$ $119 \mu \mathrm{mol} \mathrm{N} \mathrm{g}^{-1} \mathrm{DM}$, respectively. Considering all $24 \mathrm{sam}-$ ples, $\mathrm{N}_{\mathrm{t}}$ changed between 2800 and $5300 \mu \mathrm{mol} \mathrm{g}{ }^{-1} \mathrm{DM}$ (Fig. 2a). Allocation of $\mathrm{N}_{\mathrm{t}}$ to four NF-pools such as amide$\mathrm{N}$, amino- $\mathrm{N}$, nitrate- $\mathrm{N}$ and insoluble protein- $\mathrm{N}$ was positively correlated with $\mathrm{N}_{t}$, as shown by linear regressions fitted between $\mathrm{N}_{\mathrm{t}}$ and each NF-pool except amide-N. The amide- $\mathrm{N}$ remained very low both for $\mathrm{N}_{\mathrm{d}}$-low $\left(<1 \mu \mathrm{mol} \mathrm{g}{ }^{-1}\right.$ DM) and $\mathrm{N}_{\mathrm{d}}$-high $\left(27 \pm 11 \mu \mathrm{mol} \mathrm{g}{ }^{-1} \mathrm{DM}\right)$ fertilization levels but rose steeply about 12 -fold with excessive $\mathrm{N}$-supply $\left(340 \pm 61 \mu \mathrm{mol} \mathrm{g}{ }^{-1} \mathrm{DM}\right)$. Nitrate- $\mathrm{N}$ ranging from 140 to $960 \mu \mathrm{mol} \mathrm{g}{ }^{-1} \mathrm{DM}$ was the most continuously increasing NF-pool ( 7 -fold increase) followed by protein- $\mathrm{N}$ as most abundant NF-pool while amino-N was most stable in the lowest range $\left(\Delta \mathrm{N}=500-800=300 \mu \mathrm{mol} \mathrm{g}{ }^{-1} \mathrm{DM}\right)$.

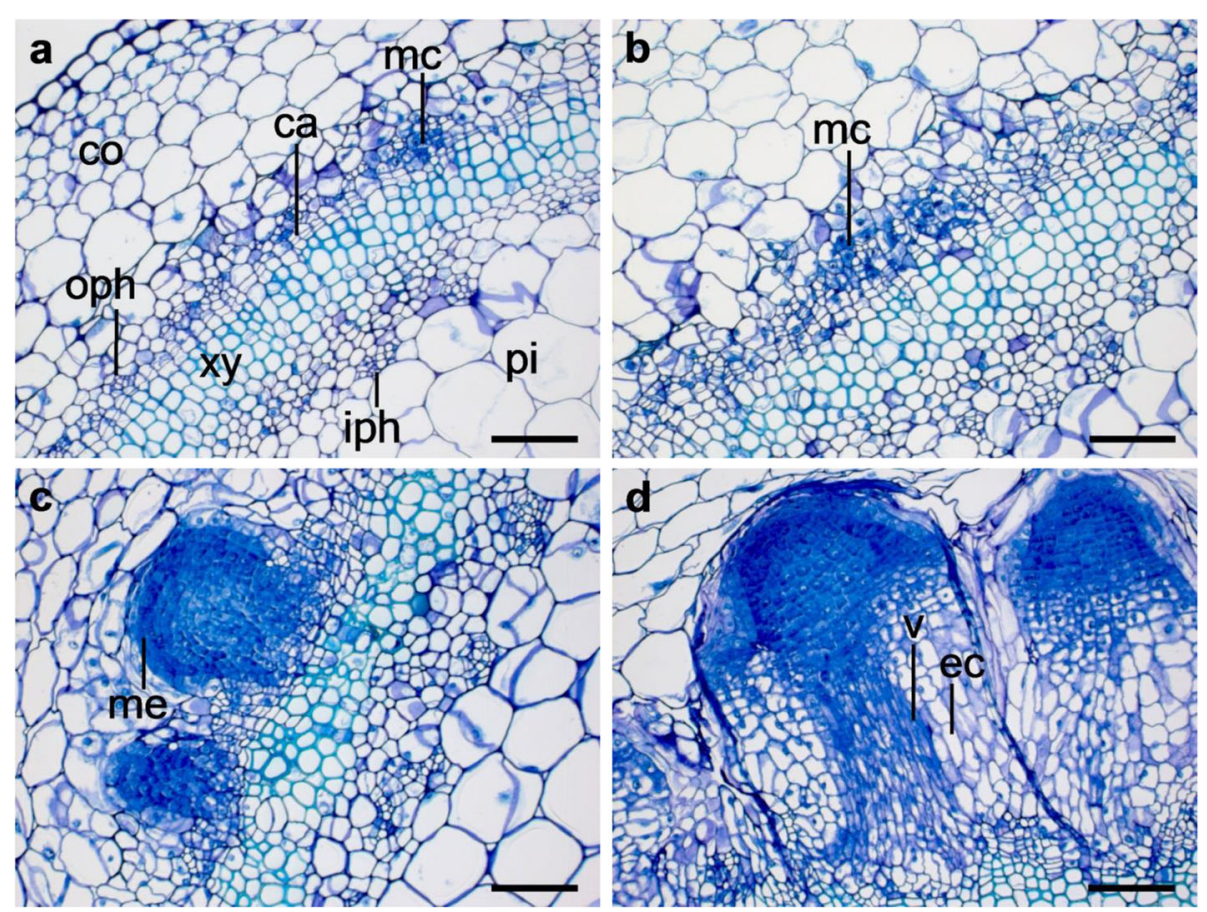

Fig. 1 Influence of reduced total nitrogen on early cytological events of AR formation in Petunia hybrida. Cuttings with two nitrogen levels, (Panels a, c) N-low at $2570 \mu \mathrm{mol} \mathrm{N}$ and (Panels b, d) N-high at $3625 \mu \mathrm{mol} \mathrm{N}_{\mathrm{t}}$ were excised from donor plants and immediately inserted into perlite for AR formation with assimilatory light. All micrographs represent cross-sections of the stem base from 1-4 mm above the excision site with the most advanced structures at (Panels a, b) $72 \mathrm{~h}$ post excision (hpe) and post insertion (hpin) and (Panels c, d) 168 hpe and hpin. Sections at 72 hpin (Panels $\mathbf{a}, \mathbf{b}$ ) show the typical stem anatomy with the cortex (co), the outer phloem (oph), the cambium (ca), the xylem (xy), the inner phloem (iph) and the pith parenchyma (pi) and first meristematic cells (mc) of developing root meristems, that is, small cells with a dense cytoplasm and a large nucleus. There are only slight differences between the nitrogen levels. Sections at 168 hpin reveal that with low $\mathrm{N}$ absorption (Panel c) first root meristems (me) appear, whereas with high $\mathrm{N}$ absorption (Panel $\mathbf{d}$ ) first roots with vascular bundles $(\mathrm{v}$ ) in the center surrounded by elongated cells (ec) of the elongation zone are visible. Bars represent $100 \mu \mathrm{m}$ (Panels a to d). Remark: Ahkami et al. [8] show that at the time of excision (0 hpe) no meristematic cells of developing root meristems are present. Further details are presented in methods and with Additional file 1) Experiments of nitrogen preconditioning of cuttings and Additional file 2) Explanation of experimental designs for Exp. 7: AR-N + CYT, respectively 
a

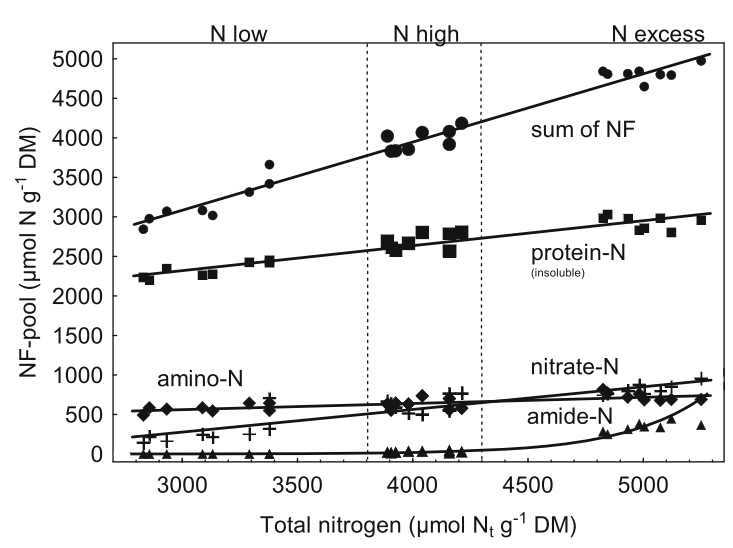

b

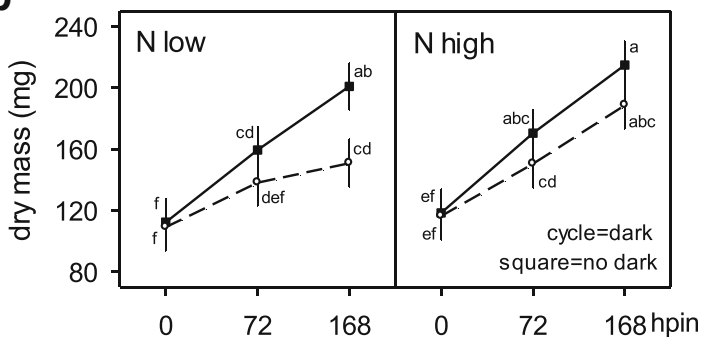

Fig. 2 (Panel a) Relationships between accumulation of total nitrogen $\left(N_{t}\right)$ and $N$ allocation to NF-pools. Axillary shoot tips of Petunia hybrida at excision time, $\mathrm{N}_{\mathrm{t}}$ allocation to metabolic NF-pools classifying amide- $\mathrm{N}$, amino- $\mathrm{N}$, insoluble protein- $\mathrm{N}$ and the sum of NF-pools in response on three levels of $\mathrm{N}_{d}$ fertilization to donor plants ( $\mathrm{N}$ low, $\mathrm{N}$ high, $\mathrm{N}$ excess). Linear correlation coefficients for nitrate-N $(r=0.91)$, amide-N $(r=0.88)$, amino-N $(r=0.74)$, insoluble protein-N $(r=0.96)$ and sum of NF-pools $(r=0.99)$ all $n=24, p<0.05$. (Panel b) Increase in shoot dry mass per cutting during AR formation (hpin) in response to two levels of $\mathrm{N}_{d}$ fertilization to donor plants ( $N$ low, $\mathrm{N}$ high) and to a pre-rooting dark exposure of cuttings (dark exposure - open circled symbols, no dark - squared symbols). Vertical bars represent $95 \%$ confidence intervals of mean values and different lower-case letters indicate significant differences. Further details of experiments, regression equations and statistics are presented in methods and with Additional file 1) Experiments of nitrogen preconditioning of cuttings, Additional file 2) Explanation of experimental designs for statistical analyses and Additional file 3) Supplemental data of figure 2 for Panel a: Exp. 1: NF-N, and Panel $\mathbf{b}$ : Exp. 9: NF-NDCR, respectively

\section{Shoot growth during AR formation}

Shoot dry mass accumulation of excised cuttings was analysed during AR formation under diurnal light at three time points of insertion in perlite $(0,72,168$ hpin $=$ hours post insertion) (Fig. 2b). In advance, cuttings of low and high $\mathrm{N}_{\mathrm{t}}$ contents ( $\mathrm{N}_{\mathrm{t}}$-low, $\mathrm{N}_{\mathrm{t}}$-high: 2900/ $\left.3500 \mu \mathrm{mol} \mathrm{N} \mathrm{g}^{-1} \mathrm{DM}\right)$ were excised from donor plants grown with two fertigation rates $\left(\mathrm{N}_{\mathrm{d}}\right.$-low and $\mathrm{N}_{\mathrm{d}}$-high: $46 / 78 \mathrm{mg} \mathrm{N}$ plant $^{-1}$ week $^{-1}$ ). Further, cuttings were exposed to dark (168 hpe $=$ hours post exision). Both, cuttings without and with dark exposure did not differ in their initial dry mass at 0 hpin whereas a high $\mathrm{N}_{\mathrm{t}}$ content enhanced dry mass by $+10 \%$ as a significant main $\mathrm{N}$-effect. Dry mass accelerated mostly with increasing time of insertion up to 168 hpin by $+79 \%$. Upon dark exposure this increase was reduced to $+50 \%$ while the delay for low $\mathrm{N}$ cuttings was most obvious at 168 hpin.

\section{AR formation with reduced $\mathrm{N}$ absorption and dark exposition of cuttings}

The effect of distinct $\mathrm{N}$ dosage to donor plants $\left(\mathrm{N}_{\mathrm{d}}\right.$-low, $\mathrm{N}_{\mathrm{d}}$-high: 51/106 mg N plant ${ }^{-1}$ week $^{-1}$ ) on $\mathrm{N}_{\mathrm{t}}$ contents in cuttings $\left(\mathrm{N}_{\mathrm{t}}\right.$-low, $\mathrm{N}_{\mathrm{t}}$-high: $\left.2575 / 3629 \mu \mathrm{mol} \mathrm{N}_{\mathrm{t}} \mathrm{g}^{-1} \mathrm{DM}\right)$ and AR formation was analysed. Total root number $($ TRN $)$ developed per cutting at day $16(384$ hpe $=$ hours post excision) differed significantly and reached 0.83 and 13.84 for low and high $\mathrm{N}_{\mathrm{t}}$ contents, respectively (Fig. 3a). For detailed analyses, all roots of a cutting (i.e. TRN) were assigned to seven root length classes to determine the root number per length class (RNC). An increased root development for high $\mathrm{N}_{\mathrm{t}}$ contents became evident in the length classes below $3 \mathrm{~cm}$ (TRN $=\sum \mathrm{RNC}=13.8$ $=6.8+4.1+1.9+0.8+0,2+0+0)$, and a significant reduction was observed with low $\mathrm{N}_{\mathrm{t}}$ contents $(\mathrm{TRN}=\Sigma$ $\mathrm{RNC}=0.83=0.68+0.14+0.01+0+0+0+0)$. Subsequently, the effect of a pre-rooting dark exposure of cuttings on $\mathrm{AR}$ formation was evaluated with cuttings grown at high $\mathrm{N}_{\mathrm{d}}$ supply to donor plants to prevent $\mathrm{N}$ limitation in cuttings (Fig. 3b). Excised cuttings were exposed to dark for 7 days (168 hpe) before perlite insertion. Sixteen days after excision (384 hpe) cuttings developed a TRN of 26.8 roots per cutting. At the same time (384 hpe) they developed considerably less roots (TRN $=19.9)$ when no dark was applied and perlite insertion was performed immediately after excision. The RNC analysis showed a prerequisite for pre-rooting dark treatment to increase root numbers in the second and third classes. However, cuttings without dark exposure developed in average two roots more in the first class $<1 \mathrm{~cm}$ (Fig. 3b). These results substantiated by a larger experiment showed that an enhanced AR formation 384 hpe led to an increase of TRN by $73 \%$ (15 vs. 26) and of TRL by $110 \%$ (that is 20 vs. $42 \mathrm{~cm}$ total root length) with low and high $\mathrm{N}$ supply $\left(\mathrm{N}_{\mathrm{d}}\right.$-low, $\mathrm{N}_{\mathrm{d}}$-high: 55/ $90 \mathrm{mg} \mathrm{N}$ plant $^{-1}$ week $^{-1}$ ), respectively (Fig. 3c, d). In contrast, in the same experiment a treatment combination of both the donor plant $\mathrm{N}$ dosages and dark exposure resulted in an increase of TRN by $+30 \%$ and of TRL by $+40 \%$ in cuttings with a low $\mathrm{N}_{\mathrm{t}}$ while cuttings with a high $\mathrm{N}_{\mathrm{t}}$ had slightly fewer $(-14 \%)$ and shorter roots $(-15 \%)$ (Fig. 3c, d). $\mathrm{N}_{\mathrm{t}}$ contents ranged from 2400 to $3900 \mu \mathrm{mol} \mathrm{N} \mathrm{g}^{-1} \mathrm{DM}$ with $\mathrm{N}_{\mathrm{d}}$-low and $\mathrm{N}_{\mathrm{d}}$-high dosages $\left(51 / 106 \mathrm{mg} \mathrm{N}\right.$ plant $^{-1}$ week $\left.^{-1}\right)$ and no dark exposure, respectively (Fig. 3e, f, g, h). 
a

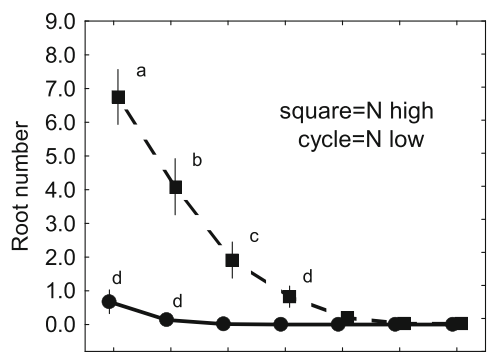

b

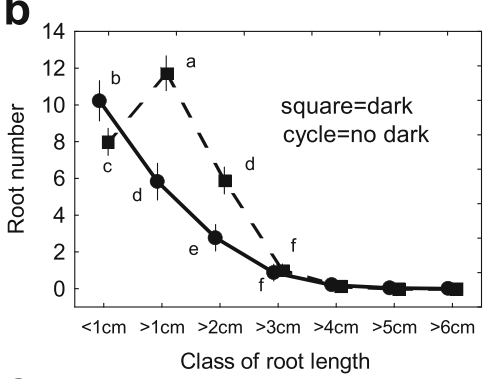

C
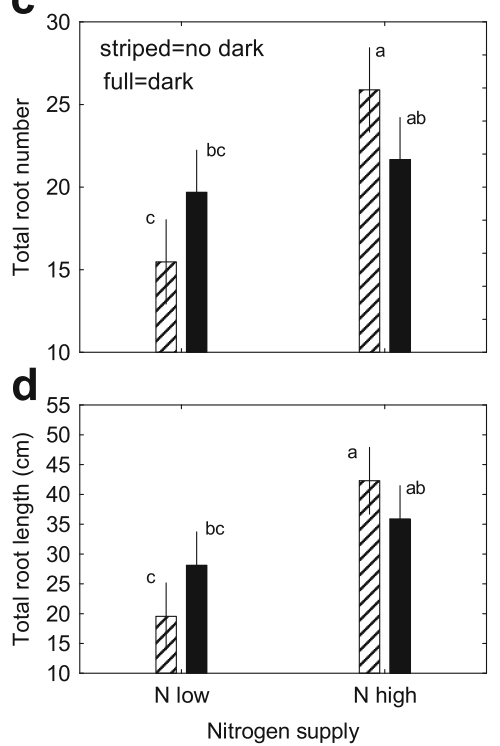

e
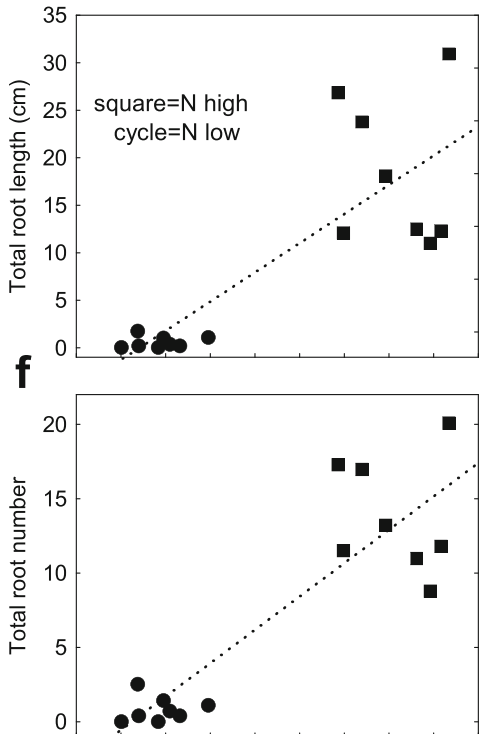

g

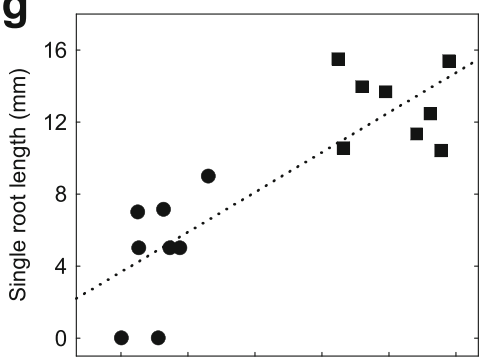

h

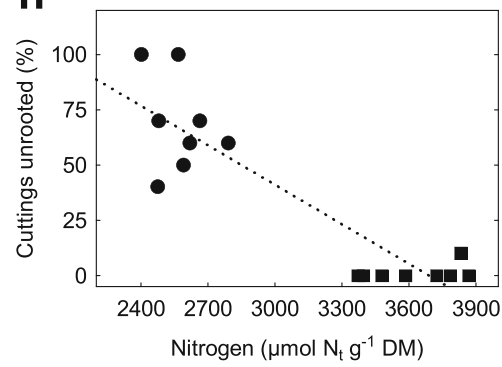

Fig. 3 Adventitious root formation 384 hpe with cuttings of Petunia hybrida: (Panel a) Root number per length class (RNC) with two levels of total nitrogen content $\left(\mathrm{N}_{t}\right)$ (cycles $=\mathrm{N}$-low, squares $=\mathrm{N}$-high). (Panel b) RNC response to dark exposure (squares $=$ dark, cycles $=$ no dark). (Panels $\mathbf{c}$ and $\left.\mathbf{d}\right)$ Response of total root number (TRN) and total root length (TRL) on combinations of two $N_{t}$ levels and dark exposure (striped bars $=$ no dark, full bars = dark). (Panels $\mathbf{e}$ to $\mathbf{h}$ ) Regression relationships between $N_{t}$ contents in unrooted cuttings and their final root development at different $N_{d}$ fertilization levels to donor plants (cycles $=$ N-low, squares $=\mathrm{N}$-high) $(\mathrm{E}:$ Total root length $-\mathrm{TRL}$, F: Total root number $-\mathrm{TRN}$, G: Mean length per single root $-\mathrm{SRL}, \mathrm{H}$ : Unrooted cuttings - URC. (Panels a to $\mathbf{c}$ ) Vertical bars represent $95 \%$ confidence intervals of mean values and different lower-case letters indicate significant differences. (Panels e to $\mathbf{h})$ Linear correlation coefficients: Panel $\mathbf{e}(r=0.82)$, Panel $\mathbf{f}(r=0.88)$, Panel $\mathbf{g}(r=0.84)$ and Panel $\mathbf{h}(r=0.89)$ all with $n=16, p<0.05$. Further details of experiments, rating of rooting (range per each class of root length $=1 \mathrm{~cm}$ ), statistics and regression equations are presented in methods and with Additional file 1) Experiments of nitrogen preconditioning of cuttings, Additional file 2) Explanation of experimental designs for statistical analyses and Additional file 3) Supplemental data of figure 3 for Panel a: Exp. 7: AR-N+CYT; Panel b Exp. 4: AR-D; Panels c and d: Exp. 2: AR-ND, and Panels e, f, g, h: Exp. 7: AR-N +CYT, respectively

Regression analysis resulted in positive relationships for $\mathrm{N}_{\mathrm{t}}$ with TRL, TRN and single root length (SRL) (Fig. 3e, f, g) and negative with percentage of unrooted cuttings at 384 hpe (Fig. 3h).

\section{Nitrogen content and $\mathrm{N}$ allocation in unrooted cuttings and during AR formation}

The low and high nitrogen fertilisation regime $\left(\mathrm{N}_{\mathrm{d}}\right)$ of donor plants resulted in two different $\mathrm{N}_{\mathrm{t}}$ absorption 
levels in cuttings while dark exposure of cuttings (as indicated by dotted lines in Fig. 4) remained without any impact on $\mathrm{N}_{\mathrm{t}}$ contents (Fig. 4a, f). In contrast, after cuttings had been planted (inserted) into perlite and exposed to diurnal light a longer time post insertion resulted in continuous decreases of $\mathrm{N}_{\mathrm{t}}$ contents in both immediately planted and dark pre-exposed cuttings (Fig. 4f). Allocations of $\mathrm{N}_{\mathrm{t}}$ to single NF-pools were

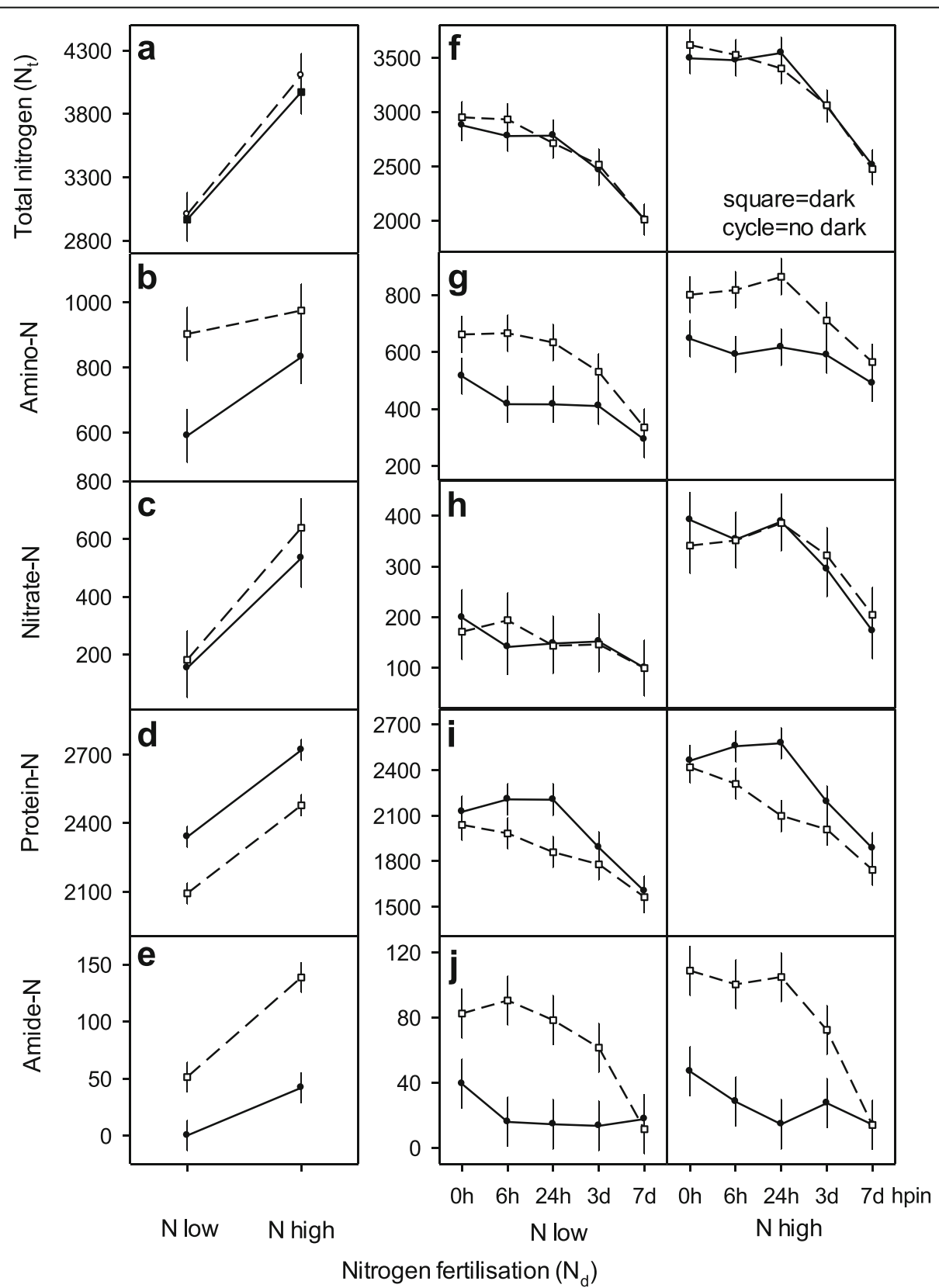

Fig. 4 Change of total nitrogen $\left(N_{t}\right)$ and NF-pools in cuttings of Petunia hybrida with graduated nitrogen fertilisation $\left(N_{d}\right)$ to donor plants, dark exposure and AR formation. (Panels $\mathbf{a}, \mathbf{b}, \mathbf{c}, \mathbf{d}, \mathbf{e}$ ): Full cycles and open squared symbols connected with full and intermittent lines show cuttings directly at severance (0 hpe) and after $168 \mathrm{~h}$ dark exposure (168 hpe), respectively. (Panels $\mathbf{f}, \mathbf{g}, \mathbf{h}, \mathbf{i}, \mathbf{j})$ : Full cycles and open squared symbols connected with full and intermittent lines represent cuttings at specific times post insertion for AR formation $(0,6,24,72,168 \mathrm{hpin}$, corresponding days are shown in the x-axis: $3 \mathrm{~d}$, $7 \mathrm{~d}$ ) at 0 hpe and after $168 \mathrm{~h}$ dark exposure (168 hpe), respectively. All data are given in $\mu \mathrm{mol} \mathrm{N} \mathrm{g}^{-1} \mathrm{DM}$. Multifactorial ANOVA's revealed significant main and interaction effects for $\mathrm{N}_{\mathrm{d}}$-levels $p<0.01$ (Panels $\mathbf{a}, \mathbf{c}, \mathbf{d}, \mathbf{f}, \mathbf{g}, \mathbf{i}, \mathbf{j}$ ), for dark exposure $p<0.00001$ (Panel $\mathbf{d}$ ), for time post insertion $p<0.0001$ (Panel $\mathbf{f}$ ), for $\mathrm{N}_{\mathrm{d}}$-levels $\times$ dark exposure $p<0.05$ (Panel $\mathbf{b}, \mathbf{e}$ ), for $\mathrm{N}_{\mathrm{d}}$-levels $\times$ time post insertion $p=0.01$ (Panel $\mathbf{h}$ ), for dark exposure $\times$ time post insertion $p<0.001$ (Panel $\mathbf{g}$, i, j). Vertical bars represent $95 \%$ confidence intervals of mean values. Further details of experiments and statistics are presented in methods and with Additional file 1) Experiments of nitrogen preconditioning of cuttings, Additional file 2) Explanation of experimental designs for statistical analyses and Additional file 3) Supplemental data of figure 4 for Exp. 6: NF-ND (with Panels $\mathbf{a}, \mathbf{b}, \mathbf{c}, \mathbf{d}, \mathbf{e}$ ) and for Exp. 9: NF-NDCR (with Panels $\mathbf{f}, \mathbf{g}, \mathbf{h}, \mathbf{i}, \mathbf{j}$ ), respectively 
affected quite differently by external factors (i.e. $\mathrm{N}_{\mathrm{d}}$ level, dark exposure). Amino-NF accumulated $12-25 \%$ of $\mathrm{N}_{\mathrm{t}}$, with both elevated $\mathrm{N}_{\mathrm{d}}$ levels and dark exposure increasing amino- $\mathrm{N}$ in excised cuttings (0hpe) and in darkexposed cuttings (168 hpe) (Fig. 4b, g). Amino-N decreased continuously with longer time post insertion (Fig. 4g). While 5-18 \% of $\mathrm{N}_{\mathrm{t}}$ were allocated to nitrate- $\mathrm{N}$ at the two $\mathrm{N}_{\mathrm{d}}$ levels, the dark exposure of cuttings did not change nitrate- $\mathrm{N}$ content (Fig. $4 \mathrm{c}, \mathrm{h}$ ). In contrast, $\mathrm{N}_{\mathrm{d}}$ level and increasing time post insertion resulted in distinct reduction of nitrate- $\mathrm{N}$ (Fig. 4h). Insoluble proteinNF was most abundant and comprised $50-70 \%$ of $\mathrm{N}_{t}$ (Fig. 4d, i). An increased $\mathrm{N}$ supply enhanced protein-NF followed by a decrease upon dark exposure at both $N_{d}$ supply levels (Fig. 4d). Dark treatment accelerated subsequent reduction of protein-NF with longer time post insertion and exposure to diurnal light. With both $\mathrm{N}_{\mathrm{d}}$ levels, largest divergence occurred among cuttings with and without dark treatment 24 hpin. Finally, protein-NF similarly decreased 168 hpin to lowest amounts irrespective of dark treatment (Fig. 4i). Amide-N as smallest NF-pool accumulated merely $0-3.5 \%$ of $\mathrm{N}_{\mathrm{t}}$ (Fig. $4 \mathrm{e}, \mathrm{j}$ ). The $\mathrm{N}_{\mathrm{d}}$ level and dark exposure raised the amide-NF up to $42 \mu \mathrm{mol}$ in excised cuttings ( 0 hpe) and up to $140 \mu \mathrm{mol}$ in dark-exposed cuttings (168 hpe). Dark exposure released much more amide- $\mathrm{N}$ within high $\mathrm{N}_{\mathrm{t}}$ cuttings compared to low $\mathrm{N}_{\mathrm{t}}$ cuttings (Fig. 4e). Regardless of a differential accumulation of amide- $\mathrm{N}$ in excised cuttings or after dark exposure, amide- $\mathrm{N}$ declined largely with increasing time post insertion $(<18 \mu \mathrm{mol}$ after 168 hpin) with both low and high $\mathrm{N}_{\mathrm{d}}$ supply. Thereby different reduction rates proved dark exposure and time post insertion as variation sources (Fig. 4j).

\section{Change of free amino acids upon raising nitrogen nutrition and dark exposure}

Free amino acids were examined in source and sink tissues (leaf and basal stem) applying three $\mathrm{N}_{\mathrm{d}}$ levels to donor plants and dark exposure of cuttings (Fig. 5). Amino acids represent a pivotal part of the amino-NF and include shared amounts of total nitrogen in plant tissues ranging from 0.075 to $0.1075 \%$ of $\mathrm{N}_{\mathrm{t}}$. The levels of total and single amino acids glu, gln, asp, asn and arg responded both to graduated $\mathrm{N}_{\mathrm{d}}$ fertilization of donor plants and dark exposure of cuttings (Fig. 5: squared symbols with dotted lines show dark responses). Further, specific patterns for amino acids were observed in the leaf and stem base of excised cuttings at 0 hpe and after dark exposure at 168 hpe, respectively (Fig. $5 \mathrm{a}$ to f). Hence, free amino acid (AA) considerably changed between 3 and $26 \mu \mathrm{mol} \mathrm{g}^{-1} \mathrm{FM}$ and accumulated between 330 and $4260 \mathrm{nmol} \mathrm{N} \mathrm{g}^{-1} \mathrm{FM}=\mathrm{AA}-\mathrm{N}_{\mathrm{t}}$. AA raised in excised cuttings ( 0 hpe) with enhanced $\mathrm{N}_{\mathrm{d}}$ levels from 5 to $8 \mu \mathrm{mol} \mathrm{g}{ }^{-1} \mathrm{FM}$ in the leaf (equivalent to 590-
$1002 \mathrm{nmol} \mathrm{N}=\mathrm{AA}-\mathrm{N}_{\mathrm{t}}$ ) and from 3 to $10 \mu \mathrm{mol} \mathrm{g}^{-1} \mathrm{FM}$ in stem base (equivalent to $330-1550 \mathrm{nmol} \mathrm{N}=\mathrm{AA}-\mathrm{N}_{\mathrm{t}}$ ). Dark exposure of cuttings during $168 \mathrm{~h}$ led to a general increase, up to 4-fold of AA released in leaf and stem base while a maximum of $26 \mu \mathrm{mol} \mathrm{g}^{-1} \mathrm{FM}$ was observed in leaf at the highest $\mathrm{N}_{\mathrm{d}}$ level (Fig. 5a). As primary metabolite in $\mathrm{N}$ assimilation, glutamate concentration was at higher levels in leaf compared to stem tissue and increased with the increasing $\mathrm{N}_{\mathrm{d}}$ supply up to $2622 \mathrm{nmol}$ glu $\mathrm{g}^{-1} \mathrm{FM}$. Further, elevated $\mathrm{N}_{\mathrm{d}}$ levels raised glutamate in leaf of both excised (0 hpe) and dark exposed cuttings (168 hpe). While $\mathrm{N}$ supply increased from high $\mathrm{N}_{\mathrm{d}}$ to excess $\mathrm{N}_{\mathrm{d}}$, the glu reduction in stem base showed an interacting effect among $\mathrm{N}_{\mathrm{d}}$-level and tissue type. Besides this, dark exposure decreased glu in leaf partly at distinct $\mathrm{N}_{\mathrm{d}}$ levels ( 380 nmol glu g $\left.{ }^{-1} \mathrm{FM}\right)$ (Fig. 5b). Altogether, glutamate accumulated between 73 and $250 \mathrm{nmol} \mathrm{N}_{\mathrm{t}}$ in response to different nitrogen levels and dark exposure. In excised cuttings ( 0 hpe) aspartate also increased with increasing $\mathrm{N}_{\mathrm{d}}$ supply. In contrast to glu, in leaf and stem tissue an increase was observed for asp in response to dark exposure. Highest asp-increase induced by dark was monitored with low $\mathrm{N}$ cuttings (Fig. 5c). Driven by three variation sources, asp accumulated between 32 and $276 \mathrm{nmol} \mathrm{N}$. Arginine (arg) in stem and leaf tissues of excised cuttings ( 0 hpe) accumulated at very low

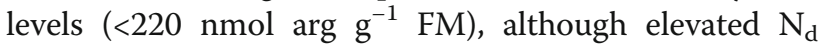
levels increased arg slightly in the leaf and decreased it marginally in the stem. However, a dark exposure of cuttings (168 hpe) resulted in tremendous, almost 9-fold increase of up to $1734 \mathrm{nmol}$ arg especially in leaf tissues grown at high $\mathrm{N}_{\mathrm{d}}$ supply (Fig. $5 \mathrm{~d}$ ) while $\mathrm{N}$ amounts allocated to the arg pool changed between 10 and $461 \mathrm{nmol}$ $\mathrm{N}_{\mathrm{t}}$. Glutamine (gln) in cuttings (0 hpe) reflected the $\mathrm{N}_{\mathrm{d}}$ levels to donor plants in a tissue specific manner. At elevated $\mathrm{N}_{\mathrm{d}}$ level it increased in the stem about 17-fold up to $4341 \mathrm{nmol}$ gln $\mathrm{g}^{-1} \mathrm{FM}$. The dark exposure (168 hpe) reduced gln in leaf tissue particularly at raised $\mathrm{N}_{\mathrm{d}}$ levels, but caused contrasting responses in stem base tissue among low and raised $\mathrm{N}_{\mathrm{d}}$ levels (Fig. 5e). The $\mathrm{N}_{\mathrm{d}}$ level remained the critical source of variation for gln in stem base while dark exposure was the important factor in the leaf. Coherent $\mathrm{N}_{\mathrm{t}}$ allocations to the glutamine pool ranged from 42 to 168 and 53 to $832 \mathrm{nmol} \mathrm{N}_{\mathrm{t}}$ in leaf and stem tissue, correspondingly. Biosynthesis of asparagine involves aspartate and glutamine as the ammonium acceptor and donor, respectively. Asparagine (asn) increased in excised cuttings ( 0 hpe) with $\mathrm{N}_{d}$ levels in a tissue specific response. It remained very low in the leaf $\left(\leq 93 \mathrm{nmol}\right.$ asn $\left.\mathrm{g}^{-1} \mathrm{FM}\right)$ and accumulated in significant amounts only in stem base at high $\mathrm{N}_{\mathrm{d}}$ levels $(\leq 1226 \mathrm{nmol}$ asn $\mathrm{g}^{-1} \mathrm{FM}$ ). In contrast, a dark exposure (168 hpe $=$ hde) caused strong specific increases in leaf and stem tissues at raising $\mathrm{N}_{\mathrm{d}}$ levels with up to $10,147 \mathrm{nmol}$ asn $\mathrm{g}$ 


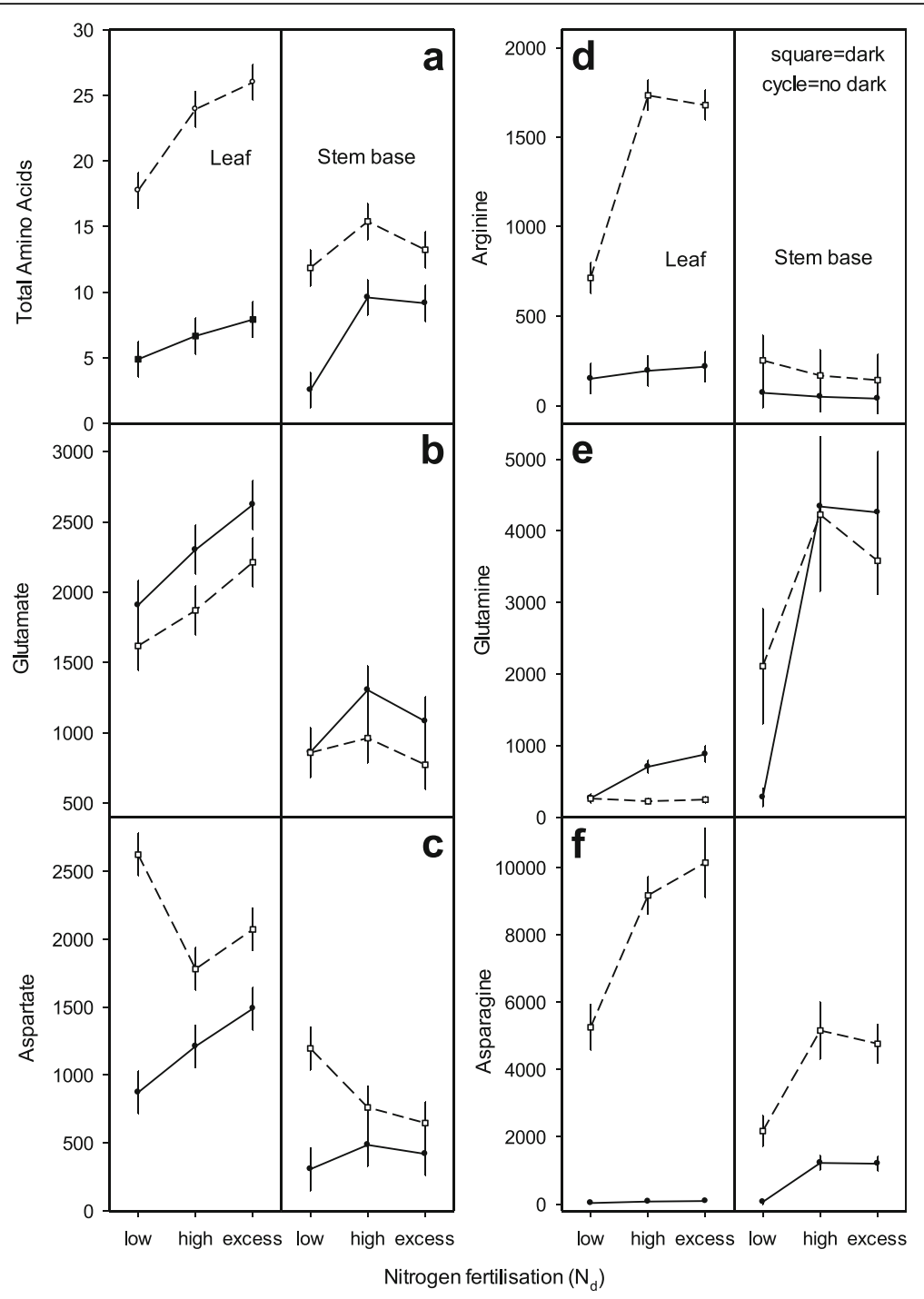

Fig. 5 Change of proteinogenic amino acids in leaf and stem base with cuttings of Petunia hybrida in response to graduated nitrogen fertilisation $\left(N_{d}\right)$ to donor plants and dark exposure. Levels: low, high and excess $N_{d}$ and $168 \mathrm{~h}$ dark exposure of cuttings ( $\left.168 \mathrm{hpe}, 10^{\circ} \mathrm{C}\right)$. Panels a to f: Full cycles and open squared symbols connected with full and intermittent lines represent cuttings directly at severance ( 0 hpe) and after dark exposure, respectively. Total amino acids are given as $\mu \mathrm{mol} \mathrm{g}{ }^{-1} \mathrm{FM}$ and single amino acids as nmol g $\mathrm{g}^{-1} \mathrm{FM}$, respectively. Multifactorial ANOVA's revealed significant main and interaction effects for $\mathrm{N}_{\mathrm{d}}$-levels $\times$ dark exposure $\times$ tissue type $p<0.00001$ to $p<0.05$ (Panels $\mathbf{a}, \mathbf{c}, \mathbf{d}, \mathbf{e}, \mathbf{f}$ ), for $\mathrm{N}_{\mathrm{d}}$-levels $\times$ tissue type $p<0.00001$ (Panel b), for dark exposure $p<0.000001$ (Panel b). Vertical bars represent $95 \%$ confidence intervals of mean values. Further details are presented in methods and with Additional file 1) Experiments of nitrogen preconditioning of cuttings, Additional file 2) Explanation of experimental designs for statistical analyses and Additional file 3) Supplemental data of figure 5 for Exp. 3: AA-ND, respectively

${ }^{-1}$ FM (Fig. 5f). Highest relative asn increase was established within the low $\mathrm{N}_{\mathrm{d}}$ level especially in leaf and, to a lower extent in stem (leaf vs. stem: $\mathrm{N}_{\text {low }}=164-$ vs. 33fold, $N_{\text {high }}=121$ - vs. 4-fold; $N_{\text {excess }}=105$ - vs. 4-fold). Allocation of $\mathrm{N}_{t}$ to the asparagine pool reached a tremendous range among 7 and $2151 \mathrm{nmol} \mathrm{N} \mathrm{t}_{\mathrm{t}}$. In addition, the impact of dark exposure on the amino acid accumulation coincided with nitrogen fluxes to the asparagine, aspartate and arginine pools, which hold up to $77 \%$ of AA- $\mathrm{N}_{\mathrm{t}}$ in the leaf, while stem tissue contained up to $74 \%$ of the AA- $\mathrm{N}_{t}$ as glutamine and asparagine.
Change of free amino acids in three different conditions To investigate the pattern of amino acid changes in leaf and basal stem of cuttings upon dark exposure a factorial design involving three environment treatments of cuttings (rooting, dark exposure, rooting after dark exposure) and five time points within each environment was studied in more detail (Fig. 6). With adequate $\mathrm{N}_{\mathrm{d}}$ supply excised cuttings (0 hpe) initially contained 15 and $9 \mu \mathrm{mol} \mathrm{AA} \mathrm{g}^{-1} \mathrm{FM}$ in stem and leaf tissues, respectively (Fig. 6a). The immediate perlite insertion for rooting under diurnal light resulted at 24 hpe in significant AA reduction followed at 72 hpe by 


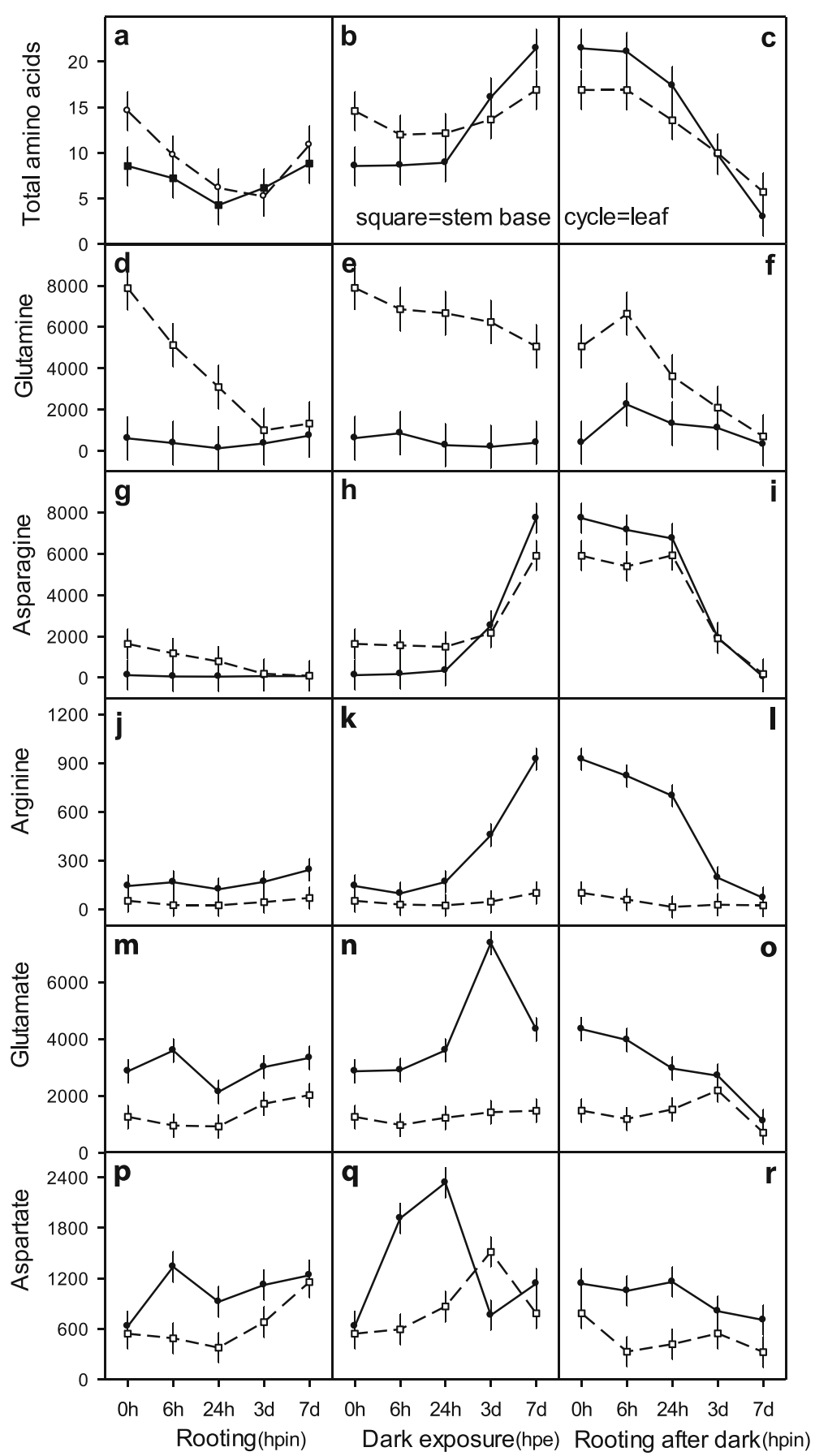

Fig. 6 Course of total and single amino acids in leaf and stem base of Petunia hybrida cuttings exposed to three environment conditions immediately planted for rooting, under dark exposure, planted for rooting after dark - and sampled at five exposition times $(0,6,24,72,168 \mathrm{hpin}$ or hpe, corresponding days are shown in the $\mathrm{x}$-axis: $3 \mathrm{~d}, 7 \mathrm{~d}$ ), respectively. Panels a to $\mathbf{r}$ : Full cycles and open squared symbols connected with full and intermittent lines represent leaf and steam base tissues, respectively. Total (free) amino acids are given as $\mu \mathrm{mol} \mathrm{g}^{-1} \mathrm{FM}$ and single amino acids as $\mathrm{nmol} \mathrm{g} \mathrm{g}^{-1} \mathrm{FM}$, respectively. Multifactorial ANOVA's revealed significant interaction effects for environment condition $\times$ exposition time $\times$ tissue type $p<0.00001$ to $p<0.05$ (Panels $\mathbf{a}-\mathbf{b}-\mathbf{c}, \mathbf{d}-\mathbf{d}-\mathbf{e}-\mathbf{f}, \mathbf{g}-\mathbf{h}-\mathbf{i}, \mathbf{j}-\mathbf{j} \mathbf{-}-\mathbf{l}, \mathbf{m}-\mathbf{n}-\mathbf{o}, \mathbf{p}-\mathbf{q}-\mathbf{r}$ ). Vertical bars represent $95 \%$ confidence intervals of mean values. Further details of experiments and statistics are presented in methods and with Additional file 1) Experiments of nitrogen preconditioning of cuttings, Additional file 2) Explanation of experimental designs for statistical analyses and Additional file 3) Supplemental data of figure 6 for Exp. 5: $A A-D C R$, respectively 
a significant recovery in leaf and stem (Fig. 6a). Under dark exposure, the AA levels initially declined slightly in stem and remained unchanged in leaf until 24 hpe. Prolonged dark exposure raised AA strongly up to 168 hpe in stem and leaf $(+5$ and $+12 \mu \mathrm{mol})$, respectively (Fig. $6 \mathrm{~b})$. When dark pre-exposed cuttings were planted (i.e. inserted to perlite) and exposed to diurnal light this was followed by a 3- and 7-fold AA reduction in stem and leaf tissues, respectively (Fig. 6c). Altogether, increase and decrease rates of AA in leaf exceeded those in stem tissue (Fig. 6b, c).

At time of cutting excision, among free amino acids, glutamine was initially (0 hpe) highest in the stem base (stem/leaf: 7881/601 nmol gln $\mathrm{g}^{-1} \mathrm{FM}$ ). The immediate insertion for rooting initiated strong gln reduction to lowest levels in leaf (24 hpe) and stem base (72 hpe). Until 168 hpe gln recovered in leaf to initial levels but only slightly in stem (Fig. 6d). The dark exposure of cuttings ( 0 hde) reduced gln concentration in stem base by $36 \%$ until 168 hde and decreased it to low initial levels in the leaf (Fig. 6e). The rooting after dark caused transient gln increases in stem and leaf followed by a reduction in both tissues to lowest levels at 168 hpe (Fig. 6f).

Asparagine was low in stem base and leaf tissue (0 hpe stem/leaf: 1634/122 nmol asn $\mathrm{g}^{-1} \mathrm{FM}$ ). A direct insertion for rooting caused asn reduction in stem and remained at low levels in leaf (Fig. 6g). During the first day of dark exposure asn decreased slightly in stem base and increased moderately in the leaf. In contrast, further dark exposure (168 hde) resulted in an increase of asn up to 23-fold in leaf, starting before 72 hde and 4-fold in stem starting after 72 hde (Fig. 6h). An insertion of dark exposed cuttings led to no change of asn in stem base up to 24 hpin and to a slight decrease in leaf (Fig. 6i) and strongly decreased, thereafter, both in stem (34-fold) and leaf (169-fold) and reached lowest levels at $168 \mathrm{hpin}$ (Fig. 6i). Arginine was low (stem/leaf: 52/143 nmol arg g $\left.{ }^{-1} \mathrm{FM}\right)$ in stem base and leaf tissue and remained unchanged until 168 hpe (Fig. 6j). Dark exposure did not change arg significantly in stem while it increased strongly up to 9-fold until 7d (923 nmol arg) (Fig. 6k). With subsequent rooting after dark period arg reduction was evident in both stem and leaf during the first day. In the further course, arg remained at low levels in stem while a 10-fold reduction of arg occurred in leaf tissue (Fig. 6l).

Glutamate accumulated in stem at lower levels when compared to leaf (0 hpe stem/leaf: 1254/2861 nmol glu g

${ }^{-1}$ FM) (Fig. 6m). A direct insertion for rooting resulted in a slight increase of glu only in leaf and was reduced in both tissues to a transient minimum at day one, and restored finally beyond initial levels. Dark exposure resulted in transient increase of glu at 72 hpe in leaf (7378 nmol glu) while it remained unchanged in stem (Fig. 6n). With rooting after dark treatment, continuous glu reduction was observed in the leaf whereas, in stem glu declined only between 72 and 168 hpe (Fig. 6o).

Aspartate started at low levels (0 hpe stem/leaf: 542/ $629 \mathrm{nmol}$ asp g $\left.{ }^{-1} \mathrm{FM}\right)$. With direct rooting asp elevated only in leaf (6 hpe: $1338 \mathrm{nmol}$ asp), decreased 24 hpe transiently in stem and leaf, and increased 168 hpe beyond initial levels (Fig. 6p). At dark exposure, asp did not change at 6 hde in the stem, rose at 72 hde to a temporary peak and decreased finally to initial levels. In the leaf, asp increased immediately until 24 hde to a maximum (2336 nmol asp), decreased at 72 hde to a minimum (761 nmol asp) and ended at 168 hde in a 2-fold increase (1138 nmol asp) (Fig. 6q). During rooting after dark treatment, asp remained unchanged in the leaf at 24 hpe and resulted in a continual decrease afterwards. In stem base, a reduction of asp was followed by a peak at $72 \mathrm{hpe}$ and decreased to lowest levels in all three environment conditions (Fig. 6r).

\section{Course of soluble protein during AR formation}

Soluble protein was examined in cuttings during AR formation under diurnal light. Environmental influence was assayed in a factorial design and included $\mathrm{N}_{\mathrm{d}}$ supply levels to donor plants, dark exposure of cuttings, five time points after planting onto perlite for AR formation (i.e. insertion) and two tissues (Fig. 7). A direct insertion started at 0 hpe at 1.6-fold higher protein in leaf versus stem (1158/ $738 \mu \mathrm{g} \mathrm{g}^{-1}$ FM) (Fig. 7a, b). Then, its transient decrease in stem coincided at 6 hpin with an increase in leaf and rose at 168 hpin accordingly in both tissues to highest levels. In contrast, dark exposed cuttings (168 hde) at insertion (0 hpin) showed elevated protein in leaf only $(3301 \mu \mathrm{g})$ followed by a decrease at 24 hpin ( 168 hde +24 hpin $=192$ hpe) and dropped to a level as in freshly excised cuttings (Fig. 7a, b). A direct insertion started 0 hpe at similar protein level for both $\mathrm{N}_{\mathrm{d}}$ levels and increased continuously for 168 hpin (Fig. 7c, d). In dark exposed cuttings (168 hde), protein was increased at insertion (168 hde +0 hpin) but did not differ for $\mathrm{N}_{\mathrm{d}}$ levels. However, at 6 hpin the low $\mathrm{N}_{\mathrm{d}}$ supply resulted in a transient protein raise $(3511 \mu \mathrm{g})$ while it remained unchanged at high $\mathrm{N}_{\mathrm{d}}$ supply for 24 hpin. Thereafter, protein with both $\mathrm{N}_{\mathrm{d}}$ levels dropped for 168 hpin to levels as in freshly excised cuttings (Fig. 7c, d).

\section{Discussion}

Early events of AR formation were delayed upon reduced $\mathrm{N}_{\mathrm{t}}$ contents

Based on anatomical characteristics, the AR formation in petunia has been divided in the root initiation phase, the root primordium formation phase and the root elongation and/or emergence phase [8]. In the present investigation, two time points of AR formation have been chosen for the histological examination, the transition from the root initiation to the root primordium formation phase (72 hpin) 


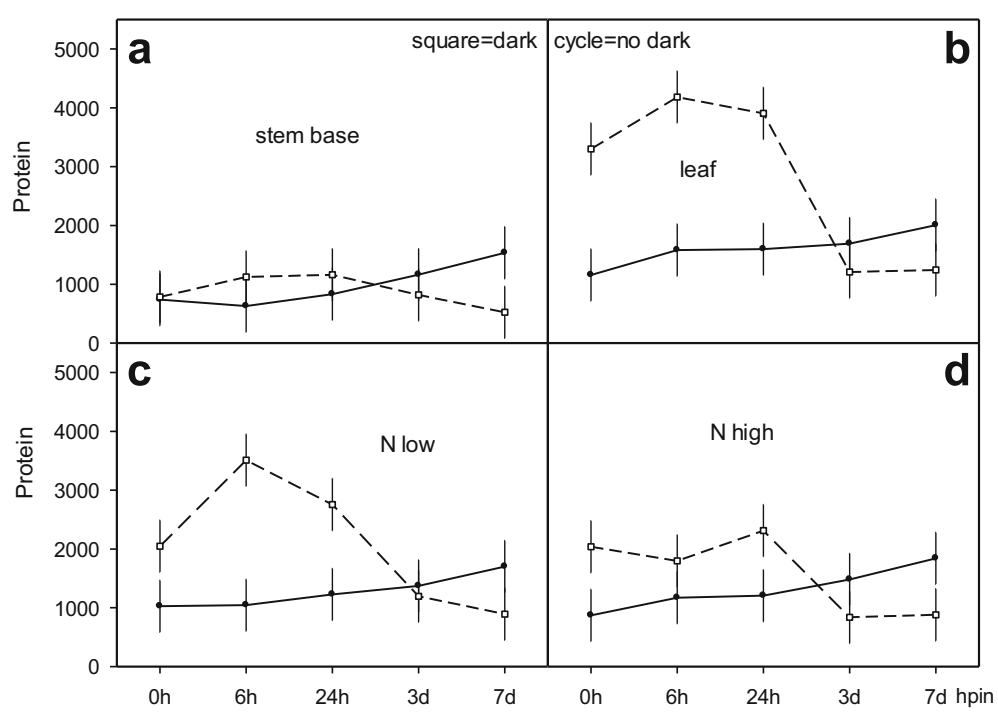

Fig. 7 Course of soluble protein in leaf and stem base with cuttings of Petunia hybrida, grown at two $N_{d}$ fertilisation levels ( $N$ low, $N$ high) to donor plants and exposed to different environment conditions - immediately planted for rooting and planted for rooting after dark - and sampled at five exposition times (0, 6, 24, 72, 168 hpin, corresponding days are shown in the x-axis: 3d, 7d). (Panels a to d): Full cycles and open squared symbols connected with full and intermittent lines represent AR formation for $168 \mathrm{hpin}$ directly after excision ( 0 hpe) and after dark exposure of cuttings (168 hpe, $10^{\circ} \mathrm{C}$ ), respectively. Multifactorial ANOVA's revealed significant interaction effects for $\mathrm{N}_{d}$-level $\times$ dark exposure $\times$ exposition time $p<0.05$ (Panels cd), for dark exposure $x$ exposition time $x$ tissue type (Panels $\mathbf{a}-\mathbf{b}$ ). Vertical bars represent $95 \%$ confidence intervals of mean values. Further details of experiments and statistics are presented in methods and with Additional file 1) Experiments of nitrogen preconditioning of cuttings, Additional file 2) Explanation of experimental designs for statistical analyses and Additional file 3) Supplemental data of figure 7 for Exp. 8: PR-NDCR, respectively

and the root primordium formation to the root elongation phase (168 hpin). The results show that the course of AR formation at 72 hpin is similar to that reported by Ahkami et al. [8], irrespective of nitrogen treatment (Fig. 1a, b). At later stage (168 hpin) first roots were observed only in the treatment with high nitrogen level (Fig. 1d). Interestingly, this observation could not be confirmed with low nitrogen (Fig. 1c) demonstrating that a critical level of nitrogen is necessary to ensure proper root initiation and a subsequent differentiation into the complete body of the root. Delayed root formation at low nitrogen supply is most likely due to a regulation of root development and metabolic adaptations via nutrients and hormones $[5,8]$. It has already been reported that an early transient rise in IAA and NO triggered anatomical changes for both AR and LR formation $[11,12,38]$ and involved basipetal auxin transport before earliest cytological events of AR formation in petunia [16].

\section{Mobile nitrogen resources raised at elevated $N_{t}$ contents}

The ranges of total nitrogen accumulation in cuttings of axillary shoot tips of Petunia hybrida are comparable to published results for chrysanthemum, pelargonium and petunia $[17,26,39]$. An increased $N_{t}$ absorption resulted in higher allocation towards soluble NF-pools while the allocation to insoluble protein- $\mathrm{N}$ decreased. However, along with increased $\mathrm{N}_{t}$ contents petunia cuttings accumulated more nitrate- and amide- $\mathrm{N}$ than amino- $\mathrm{N}$ (Fig. 2a). Planting of cuttings and subsequent exposure to diurnal light induced tremendous $\mathrm{N}_{\mathrm{t}}$ decreases during initial rootless stages indicating that all NF-pools contributed to AR formation (Fig. 4f-j).

\section{Shoot growth during AR formation responds to $\mathrm{N}_{t}$ and dark exposure}

A higher nitrogen content enhanced shoot dry mass accumulation by $10 \%$ what is comparable to earlier reports [39]. Direct rooting (i.e. planting rsp. perlite insertion at 0 hpe) caused the most significant dry mass increase throughout until 168 hpin. In contrast, after a temporary dark experience (168 hpe) the subsequent shoot growth under diurnal light (168 hpin) was mostly reduced at a low initial $\mathrm{N}$ absorption of cuttings (Fig. 2b). Considering the simultaneous dark stimulation of AR formation with a low $\mathrm{N}$ absorption (Fig. 3c, d), this stays in accordance with the finding that dark exposure enhances the sink competitiveness of the rooting zone resulting in a higher proportion of dry mass allocation towards developing roots [40].

\section{Increased $\mathrm{N}$ absorption and dark treatment improves $\mathrm{AR}$ formation}

The parameters of AR formation (TRN and RNC) were notably decreased at a lower $\mathrm{N}_{d}$ supply and reduced $\mathrm{N}_{t}$ absorption (Fig. 3a). This coincides with reports of a nitrogen limitation of AR formation in chrysanthemum, pelargonium, poinsettia and petunia $[17,26,27,39]$. In the present study, AR formation in petunia was even reduced 
at low $\mathrm{N}_{\mathrm{d}}$ supply (Fig. 3a) when $\mathrm{N}_{\mathrm{t}}$ diminished just slightly below the recommended $\mathrm{N}_{\mathrm{t}}$-range between 2750$5429 \mu \mathrm{mol} \mathrm{N}_{\mathrm{t}}$ [39] (Fig. 3e, f, g, h). Then, cuttings revealed no phenotype above the critical level for deficiency symptoms of $1471 \mu \mathrm{mol} \mathrm{N}_{\mathrm{t}}$ [41]. The dark stimulation of AR formation (Fig. 3b) supported earlier data of an increased, accelerated and synchronized rooting after dark exposure [29]. However, low and high initial $\mathrm{N}_{\mathrm{t}}$ levels confirmed the high $\mathrm{N}$ effect on AR formation only as long as no dark exposure was applied (Fig. 3c, d).

\section{Nitrogen allocation mirrors $\mathrm{N}_{\mathrm{t}}$ contents, dark exposure and period during AR formation}

Nutrient concentrations, in particular nitrate, amino acids and $\mathrm{N}_{t}$ rapidly declined at early phases of AR formation indicating a high $\mathrm{N}$ demand $[21,42,43]$. As dark stimulation of AR formation involved a strong dark induced carbohydrate starvation [29] it further implied concurrent $\mathrm{N}$ fluxes obviously contributing to improved $\mathrm{N}$ availability in the rooting zone meeting the high $\mathrm{N}$ demand at early rootless phases [8]. Although darkness did not change $\mathrm{N}_{t}$ it reduced insoluble protein- $\mathrm{N}$ at both $\mathrm{N}_{\mathrm{d}}$ supply levels (Fig. 4a, f, d, i) and warranted fluxes of released $\mathrm{N}$ into soluble amino- $\mathrm{N}$ and amide- $\mathrm{N}$ pools (Fig. 4b, g, e, j). This is in accordance with the reports that prolonged darkness affects proteolytic systems of cellular compartments and activates protein breakdown in response to carbohydrate starvation [44]. Thereby, total $\mathrm{N}$ and the nitrate-NF pool remains unaffected from darkness (Fig. 4a, f, c, h) since darkness prevents photosynthesis and concomitantly inactivates nitrate reductase and $\mathrm{N}$ assimilation [45].

\section{Amino acids show specific patterns for raised nitrogen nutrition and dark exposure}

The amino acid levels in petunia increased with both enhanced $\mathrm{N}_{\mathrm{d}}$ supply and dark exposure differing however, for both leaf and stem (Fig. 5a). Dark treatment was an exception among the other variation sources $\left(\mathrm{N}_{\mathrm{d}}\right.$-level $\mathrm{x}$ dark exposure $x$ tissue type). Interestingly, leaf dark treatment led to highest amino acid concentration with excess $\mathrm{N}_{\mathrm{d}}$ supply while amino acids in stem increased significantly, most of all with the low $\mathrm{N}_{\mathrm{d}}$ supply. Recent reports showed that $\mathrm{N}_{\mathrm{d}}$ supply is a pivotal external factor that initiates synthesis and raises amino acids along with internal nitrogen levels and altered gene transcription [46-48]. Amino acid levels also changed within different tissues and responded to other external factors as irradiance level, temperature shift and carbohydrate supply $[49,50]$. Here, an increase of AA in leaf was dependent on the amount of nitrogen supplied with glu, asp and gln as major and arg as minor amino acids (Fig. 5b, c, d, e, f). In contrast, in stem an enhanced $\mathrm{N}_{\mathrm{d}}$ supply resulted in high gln level ( 17-fold) and low levels of glu and asn. These results are in agreement with previously reported data with gln as predominant amino acid followed by glu, asn and asp in the stem of petunia and of other plant species $[8,51]$. A shift in the exogenous supply from high to excess $\mathrm{N}_{d}$ caused a stagnation (AA, gln, asn) or a slight decrease (glu, asp) of stem amino acids (Fig. 5a, b, c, e,f). This might be caused by an osmotic interference along with soil salt accumulation after excess $\mathrm{N}$ fertigation (Salt ${ }^{\mathrm{KCl}}$ equivalent and growth of cuttings see Additional file 1). In this regard it was reported that the salt stres repressed long distance amino acid transport specifically in stem tissue [52].

Although dark exposure elevated AA in leaf and stem, single amino acids responded differently in each tissue. A general shift in $\mathrm{N}$ metabolism coincided with a strong carbohydrate starvation [29, 44]. The dark-induced increases of AA mainly comprised elevated asn, asp and arg levels with tissue specific responses at the different $\mathrm{N}_{\mathrm{d}}$ supply levels (Fig. $5 \mathrm{c}, \mathrm{d}, \mathrm{f}$ ). This is also strongly supported by reports that leaves senescing in the dark showed increases in asparagine and other amino acids [53]. Further, this is strengthened by data showing that in different plants asparagine synthetase genes (AS) are repressed by light and activated by dark. Moreover, AS genes are inversely correlated with carbohydrate levels in plants while exogenous sucrose repressed AS root gene expression [54-56]. Therefore, accumulation of free asparagine and arginine - having high nitrogen to carbon ratios - are assumed to serve as $\mathrm{N}$ storage compounds which buffer critical ammonium release in darkness. The ammonium release results from dark-induced proteolysis and amino acid deamination and is driven by accelerated respiratory carbohydrate demands for tissue survival during darkness [47, 57]. Interestingly, the dark-induced increase of asp was highest at a low $\mathrm{N}_{\mathrm{d}}$ supply level in both leaf and stem tissues (Fig. 5c). This corresponds to an increase of asp found in response to low nitrogen stress among numerous metabolic adaptions in maize leaves [58]. However, while asn, asp and arg increased with dark exposure, the glu levels contrarily decreased in both tissues (Fig. 5b). Gln disappeared with dark exposure at high and excess $\mathrm{N}_{\mathrm{d}}$ supply in leaf but remained unchanged in stem (Fig. 5e). In contrast, stem tissues of low $\mathrm{N}$ cuttings showed elevated gln in response to dark exposure. Taken together, under conditions of $\mathrm{N}$ deficiency (low $\mathrm{N}_{\mathrm{d}}$ supply) the dark-induced increases of gln and asp were observed especially along with an AA rise in the stem (Fig. 5a, c, e). This might reflect an elevated dark-induced activity for $\mathrm{N}$ remobilisation by a temporary accumulation of metabolite precursors of asn synthesis like asp and gln [57]. In this regard, it was reported that protein degradation results in an increase in the Gln-synthetase/Glu-synthase (GS/GOGAT) cycle and that amounts of glu and gln increased, although overall amino acids decreased with $\mathrm{N}$ deficiency [59]. 


\section{Course of amino acids responded to distinct environment} situations

Considering high and adequate $\mathrm{N}_{\mathrm{d}}$ supply to donor plants, levels of AA and single amino acids displayed comparable ranges in two independent experiments (Figs. 5 and 6). Along with AA, gln and asn showed initial reductions in stem base up to 72 hpin (Fig. 6a, d, g), while glu and asp in stem base turned around to recover before 72 hpin (Fig. $6 \mathrm{~m}, \mathrm{p}$ ). The amino acid changes in stem base are in agreement with the metabolic phases for sink establishment, recovery and maintenance suggested by Ahkami et al. [8]. With high $\mathrm{N}_{\mathrm{d}}$ supply, the levels of amino acids changed differently in all tissues and conditions examined. Especially, at the end of dark exposure (168 hde/168hpe) tissue specific alterations of AA, gln, asn and arg were obvious (Figs. 5a, d, e and 6b, $\mathrm{e}, \mathrm{h}, \mathrm{k}$ ). Furthermore, the respective courses of AA and single amino acids at earlier time points imply a switch in transcriptional regulation of amino acid metabolism (between 24hde and 72 hde) caused by the low energy status $[60,61]$ and with a dark induced carbohydrate depletion in leaf tissue [29, 44, 57]. Moreover, a subsequent basipetal allocation of amino acids (after 72 hde) might be induced with a preferred early sink establishment in the stem base region of root regeneration [40, 62]. Sink cell development strongly depends upon nitrogen which is transported mainly as gln or asn, and to lesser amounts as glu or asp via the phloem [21, 63]. However, during darkness $\mathrm{N}$-rich amino acids (asn, arg) accumulated in the leaf (Fig. 6h, k) preventing ammonia toxification and using arg as precursor for a supposed $\mathrm{NO}$ signal cascade in early phases of AR formation [12, 13, 64]. The immediate and strong rise in asp level in leaf before 6 hde until 24 hde (Fig. 6q) and the subsequent increase in glu level from 24hde until 72hde (Fig. 6n) indicate a reprogramming of amino acid metabolism in darkness. In Arabidopsis, an induction of genes encoding enzymes of the asparagine biosynthetic pathway, such as glutamate dehydrogenase 2, aspartate aminotransferase, glutamate synthase and asparagine synthetase was found during $8 \mathrm{~d}$ of dark exposure [60]. Further, it was reported that $\mathrm{NAD}(\mathrm{H})$ dependent glutamate dehydrogenase is essential for plant survival during dark-induced carbon starvation [65]. Finally, a reciprocal regulation of asparagine synthetase genes by light and metabolites such as glutamine was shown [66]. This is in agreement with the decrease in courses of amino acid levels during AR formation under diurnal light and after the dark exposure (Fig. 6c, f, i, l and o) when carbohydrate biosynthesis was re-established [29].

\section{Soluble proteins undergo proteolysis in senescence}

During cutting propagation developmental and abiotic stress signals include wounding, dark exposure and root induction with e.g. changing internal $\mathrm{N}$ resources.
Thereby, reconvalescence and survival after senescence (developmental and/or dark induced) and AR formation depend on transcriptomic and metabolic adjustments to low energy status involving proteolysis and new protein synthesis $[9,67,68]$. In our study, soluble protein elevated during $7 \mathrm{~d}$ (168 hpe =hpin) in both stem and leaf and at high and low $\mathrm{N}_{\mathrm{d}}$ supply (Fig. 7). Suzuki and Kohno [21] suggested that nitrogen required by the growing parts (sinks) in the stem base comes from protein breakdown in source tissues (e.g. leaves). However, strong decreases of insoluble protein indicate $\mathrm{N}$ mobilisation during AR formation under diurnal light (Fig. 4i). At the two $\mathrm{N}$ levels proteolysis started $24 \mathrm{hpin}$ and concurred with $\sim 2$-fold soluble protein rise (Fig. 7a, b, c, d).

In contrast, the pre-rooting dark exposure of cuttings likely involved an artificially, reversible senescence and transcriptome changes [67] that induced strong protein degradation [44] and changed amino acid metabolism under low energy stress $[60,68]$. This can explain the high $\sim 4$-fold transient elevation of soluble protein especially in the leaf and at low $\mathrm{N}$ levels (Fig. 7b, c, d). Dark-induction of proteases in source tissues and corresponding sink establishment in the rooting zone with following enhanced flux of assimilates under subsequent light $[29,40,62]$ could comprise degradation of chloroplast proteins like Rubisco [69] and involve senescence-associated vacuoles [70], that release peptides and amino acids for phloem upload and transport to new sinks in basal stem $[9,62]$. This explains the positive correlation between proteins, amino acids as well as $\mathrm{N}_{t}$ and AR formation in petunia (Fig. 3e, f, g), minirose [28] and chrysanthemum [26]. While protein degradation contributes to auxin signalling by the ubiquitin-proteasome pathway [71] proteolyses selectively involve ubiquitin ligases (E3s) that control cell cycle by targeting cyclindependent kinase inhibitors [72] and thus influence lateral root and AR development [73, 74]. Hence dark stress might modulate auxin-mediated cell cycle progress and accelerate AR formation in petunia [29].

\section{Darkness induces the accumulation of free amino acids}

Based on our findings, a model for dark induced accumulations of free amino acids is presented (Fig. 8). Extended darkness results in carbohydrate depletion by rapid glycolysis and low energy status triggering the proteolysis and amino acid catabolism with glutamate as primary amino acid. By the action of aspartate-aminotransferase $($ AspAT $)=$ glutamic-oxaloacetic transaminase $(\mathrm{GOT})$ the amino group (-NH2) of glutamate is transferred to oxaloacetate (OAA) producing aspartate and alpha-ketoglutaric acid $(\alpha-K G)$. This is supported by the accumulation of aspartate (6-24 hde) and glutamate (24-72 hde) (Fig. 6n, q). 


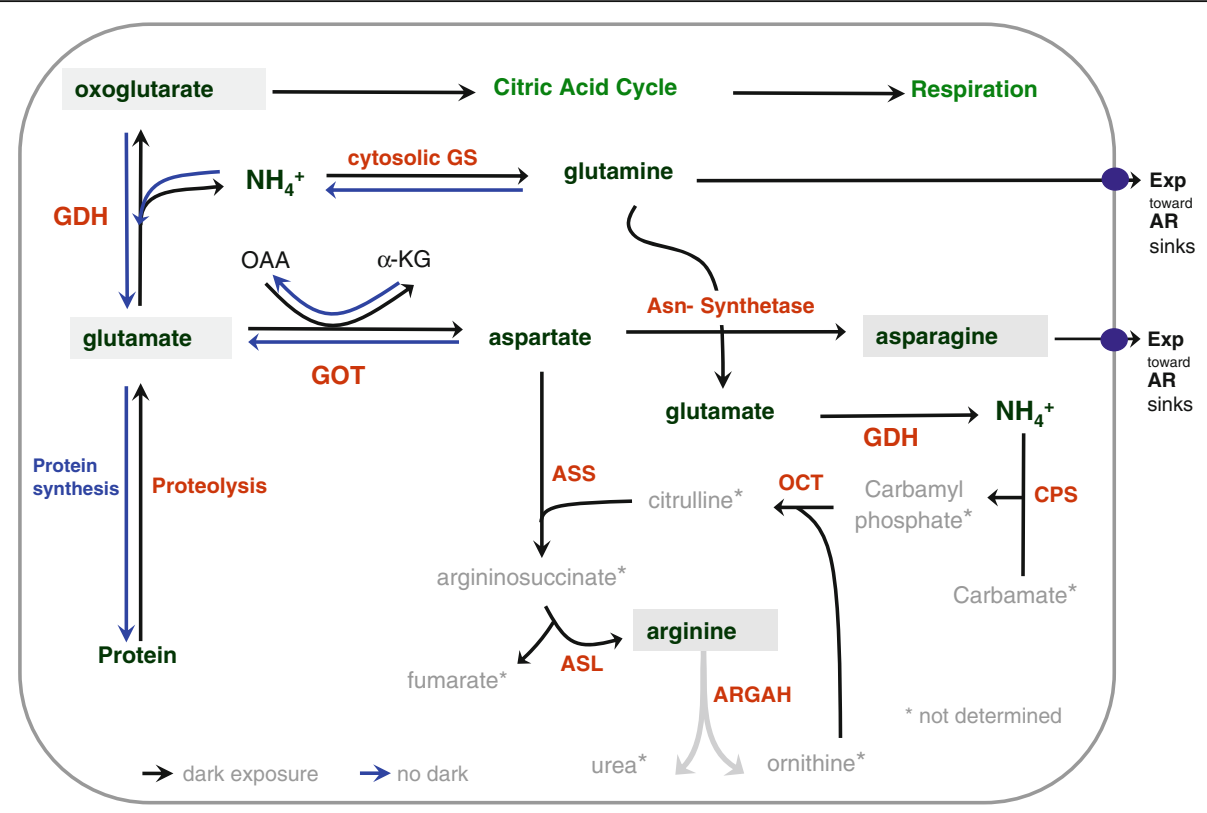

Fig. 8 Schematic representation of metabolic processes of N-remobilisation during dark-induced proteolysis on carbohydrate depletion. Extended darkness results in carbohydrate depletion and low energy status that triggers proteolysis and amino acid catabolism with glutamate as primary amino acid. GDH deaminates glutamate to oxoglutarate and free $\mathrm{NH} 4+$ that is captured by cytosolic glutamine-synthetase (GS) to produce glutamine and glutamate. Glutamine and aspartate are used by asparagine synthetase to generate glutamate and asparagine. Both, asparagine and glutamine are exported to sink tissues as a nitrogen resource. Arginine accumulates in the urea cycle to prevent NH4+ accumulation to toxic levels. Enzymes: GDH - Glutamatedehydrogenase, GS - Glutamine-synthetase, Asn - Asparagine-synthetase, GOT - Glutamic-oxaloacetic transaminase = AspAT - Aspartate-aminotransferase, ASS - Argininosuccinate-synthetase, ASL - Argininosuccinate-lyase, ARGAH - Arginine-amidohydrolase, OCT - Ornithin-carbamoyl-transferase, CPS Carbamoylphosphat-synthetase; Metabolites: a-KG - a-Ketoglutarate, OAA - Oxaloacetic acid, CP - Carbamoylphosphate, CT - Carbamate; • - Transport protein in cell membrane, black arrow - dark exposure, blue arrow - no dark

Further, $\mathrm{NAD}(\mathrm{H})$-dependent glutamate dehydrogenase (GDH) deaminates glutamate to oxoglutarate and free $\mathrm{NH} 4+$ which in turn is captured by cytosolic glutaminesynthetase (GS) to produce glutamine and glutamate being exported to sink tissues. Glutamine and aspartate are used by asparagine synthetase to generate glutamate and asparagine (24-168hde) while asparagine is exported to sink tissue as a nitrogen resource for AR formation. This process contributes also to the transient accumulation of glutamate (24-72hde) (Fig. 6n) which is again catabolised by GDH to oxoglutarate and free NH4+. To prevent NH4 + accumulation to toxic levels, $\mathrm{NH} 4+$ and carbamate are bound by the action of carba-moylphosphat-synthetase (CPS) to carbamoylphosphate. Finally, arginine accumulated (24-168hde) (Figs. 5d and 6k) in the urea cycle and might contribute to endogenous NO synthesis which is essential for the IAA signal transduction in AR formation.

\section{Conclusions}

In the present study, we first demonstrated that enhanced nitrogen concentrations of cuttings did not modify the establishment of new root meristematic cells until $72 \mathrm{~h}$. However, subsequently, an enhanced $\mathrm{N}_{\mathrm{t}}$ of cuttings accelerated further early anatomical events of differentiation during AR formation in the stem base until $168 \mathrm{~h}$, which was followed by a strong rise in the number of emerged ARs and their total length at $384 \mathrm{~h}$. Also, dark exposure stimulated AR formation in cuttings and this was most pronounced with a low $\mathrm{N}_{\mathrm{t}}$. The results further clearly showed, that the graduated $\mathrm{N}_{\mathrm{d}}$ supply to donor plants and a dark exposure of cuttings changed the accumulation of $\mathrm{N}_{t}$ and $\mathrm{N}$ allocations to metabolite pools like soluble protein, amino $\mathrm{N}$ and major amino acids of the primary $\mathrm{N}$ metabolism as glu, gln, asp, asn and arg in stem and leaf tissues, respectively. In this regard, developmental and reversible senescence adaptations of $\mathrm{N}$ metabolism with remobilization of nitrogen compounds are shown to facilitate AR formation in cuttings. Further analysis of metabolic responses and of the transcriptome including plant hormone related pathways should be combined with functional analysis of candidate factors to disentangle how nitrogen remobilization stimulates AR formation in cuttings. Finally, it was concluded that refined strategies for highest propagation rates should include nitrogen fertilization of donor plants and subsequent dark storage of cuttings. For an enhanced survival and rooting capacity improved quality assessment systems are required 
[75]. They can consider amino acid profiles and/or composite nitrogen pools as metabolic indicators of cutting quality along with carbohydrates in the global production chains for young plants.

\section{Methods}

\section{Donor plant cultivation}

Young plants of Petunia hybrida cv. Mitchell (Genotype W115) were grown from seeds in vitro and then transferred to the greenhouse [29]. Subsequently, they were transplanted into $1.1 \mathrm{l}$ pots filled with a special mix of peat based substrate without slow release fertilizers (Einheitserde Typ ED-73 with Optifer, Patzer, Sinntal-Jossa, Germany). A continued growth of side shoots from axillary nodes was induced by weekly excisions of all mature shoot tips. Every excised shoot tip contained 4-5 leaves of similar size while two axillary nodes remained on its donor shoot providing sites for the regeneration of new buds and shoots. The greenhouse climate of the stock plants was regulated by shading from excess natural irradiance (photon flux density (PPFD) $>720 \mu \mathrm{mol} \mathrm{m} \mathrm{m}^{-2} \mathrm{~s}^{-1}(400-$ $700 \mathrm{~nm})$ ), day length restriction $(10 \mathrm{~h}$ day light regulated by an opaque curtain) and heating/ventilation temperature set points (day $20 / 22{ }^{\circ} \mathrm{C}$ and night 16/ $18{ }^{\circ} \mathrm{C}$ ). The average daily light integrals (DLI), relative humidity and air temperatures in the greenhouse were registered for the 21 day periods while new side shoots developed at the donor plants before the date of excision. These 21 day averages ranged from 2.4 to $14.2 \mathrm{~mol} \mathrm{~m}^{-2} \mathrm{~d}^{-1}$ DLI $(400-700 \mathrm{~nm})$, from 55 to $77 \%$ relative humidity and from 17 to $23{ }^{\circ} \mathrm{C}$ air temperature within the four cultivation periods (for details see supplemental data in Additional files 1, 2 and 3).

Conditioning the physiology of donor plants and cuttings All donor plants initially were cultivated starting with a uniform nutrient availability, $\mathrm{pH}$ and osmotic properties in the peat substrate (Einheitserde Typ ED-73 in $\mathrm{mg} \mathrm{l}^{-1}$ : $167 \mathrm{NO}_{3}-\mathrm{N}, 75 \mathrm{P}, 133 \mathrm{~K}, 4.1 \mathrm{pH}$, salt equivalent $1.83 \mathrm{~g} \mathrm{l}$ ${ }^{-1} \mathrm{KCl}$ ). Fifteen donor plants were assembled in each of two or three treatment plots for graduated nitrogen fertigation regimes while the different treatment plots comprised each of four replication plots $(3 \mathrm{~N}$-treatments $\times 4$ replications $\times 15$ plants $=180$ plants assembled in 12 plots or $2 \mathrm{~N}$-treatments $\times 4$ replications $\times 15$ plants $=120$ plants assembled in 8 plots). The excised leafy cuttings were either transplanted immediately into a perlite substrate for adventitious root (AR) formation or exposed to a dark cool environment (see details below) prior to transplanting for AR formation.

\section{Cultivation of donor plants at graduated nitrogen} fertilization dosages

To differentiate nitrogen levels in excisable leafy cuttings, donor plants received up to three fertigation regimes which differed in nitrogen dosages only and provided a normal supply of all remaining nutrients at similar $\mathrm{pH}$ levels. In order to fine-tune nutrient dosages to environmental changes in biomass growth, peat substrate was controlled by regular chemical analyses according to Zerche and Druege [27].

The nitrogen dosages were differentiated about 14 days after transplanting and delivered by nutrient solutions (150 ml nutrient solution per plant and week) at three graduated $\mathrm{N}$-dosage regimes: $\mathrm{N}_{\mathrm{d}}$-low 41-64, $\mathrm{N}_{\mathrm{d}}$-high 78 109 and $\mathrm{N}_{\mathrm{d}}$-excess $150-179 \mathrm{mg} \mathrm{N}$ per plant and week, respectively. By this way specific total $\mathrm{N}$ dosages accumulated during the different periods of donor plant cultivation prior to each date of shoot tip excision (for details see Additional file 1). With the longest period of cultivation to the excision date each donor plant received totally 973 , 1978 and $3611 \mathrm{mg} \mathrm{N}$ in the $\mathrm{N}_{\mathrm{d}}$-low, $\mathrm{N}_{\mathrm{d}}$-high and $\mathrm{N}_{\mathrm{d}}$-excess dosage regimes, respectively.

The nutrient solutions for the different nitrogen regimes were prepared by combinations of suitable and balanced amounts of $\mathrm{NH}_{4} \mathrm{NO}_{3}\left(9 \% \mathrm{NO}_{3}-\mathrm{N}+9 \% \mathrm{NH}_{4}-\right.$ $\mathrm{N})$ and $\mathrm{Ca}\left(\mathrm{NO}_{3}\right)_{2}\left(19 \% \mathrm{Ca}+14.5 \% \mathrm{NO}_{3}-\mathrm{N}+1 \%\right.$ $\mathrm{NH}_{4}-\mathrm{N}$ ) according to Zerche and Druege [27]. All other macro- and micronutrients were added at equal amounts to these nutrient solutions using the complex fertilizer Ferty Basis $1\left(14 \% \mathrm{P}_{2} \mathrm{O}_{5}, 38 \% \mathrm{~K}_{2} \mathrm{O}, 5 \% \mathrm{MgO}\right.$, and micronutrients; Planta Düngemittel $\mathrm{GmbH}$, Regenstauf, Germany).

\section{Excision of cuttings, dark exposure and illuminated perlite insertion for AR formation}

The excision of mature cuttings (shoot tips with 4-5 leaves) started only after donor plants had received at least $4 \mathrm{~h}$ day light [29]. Cuttings were collected per nitrogen level and replication plot. For dark treatment they were placed in non-perforated plastic bags in cardboard boxes and immediately relocated to a cooled dark cabinet at $10{ }^{\circ} \mathrm{C}$ for 7 days. For AR formation under diurnal light cuttings were inserted in trays filled with perlite (Granule size 0-6 mm; Knauf Perlite GmbH, Dortmund, Germany) and placed in a climate chamber with diurnal light/dark cycles [29, 40]. Cuttings were both excised and directly inserted/planted in perlite for AR formation during 16 days or were kept in darkness for 7 days and then inserted for AR formation during 9 days ( 16 days from excision). At each excision date the defined number of cuttings was collected per replication plot and treatment combination pertaining to paralleled samplings for examinations of (i) histological stages (2 cuttings), (ii) rooting capacity (10 cuttings) and (iii) biomass growth (10 cuttings) or biochemical analyses of (iv) NF- 
pools (10-15 cuttings), (v) free amino acids ( 2 or 5 cuttings) and (vi) soluble proteins ( 2 cuttings). Thereby multifactorial experiments electively considered single treatments and or combinations of environmental factors as nitrogen level, time at dark exposure and or time after insertion (planting) and exposure to diurnal light for AR formation. Uniform time-scales were adapted to all samplings according to Klopotek et al. [29, 40] utilising either hours post excision (hpe), hours dark exposure (hde) during dark treatment and hours post insertion (hpin) during AR formation, respectively.

\section{Evaluating the capacity of AR formation}

For adventitious root formation ten cuttings per replication plot were inserted into perlite trays, watered once a day and covered with clear hoods to conserve humidity. The cultivation for AR formation continued in a phytotron for 16 or 9 days (384 hpin or 216 hpin) as defined in individual experiments. The following growth conditions were maintained at diurnal cycles: $10 \mathrm{~h}$ light/14 h dark, temperature $22{ }^{\circ} \mathrm{C}$ day $/ 20{ }^{\circ} \mathrm{C}$ night, humidity $85 \%$ day/ 60 \% night. Fluorescence tubes (Master TLD $58 \mathrm{~W} 830$, warm-white, Phillips, The Netherlands) provided the light at $100 \mu \mathrm{mol} \mathrm{m} \mathrm{m}^{-2} \mathrm{~s}^{-1}$ PPFD (400-700 nm) [29, 40].

The capacity of AR formation was rated uniformly at 384 hpe (hours post excision) and according to standard procedures $[27,29]$. This constant time period of 384 hpe coincided either with 384 hpin (hours post insertion into perlite) in case of direct planting for AR formation under diurnal light or included an initial time of 168 hde (hours dark exposure) which was finished with planting for AR formation under diurnal light for 216 hpin (i.e. 384 hpe $=168$ hde +216 hpin) as defined in the experiment. Accordingly the number of adventitious roots was counted at each inserted cutting while all the roots were assigned to their classes of root length in $10 \mathrm{~mm}$ ranges. The total number of roots per inserted cutting (TRN), the root number per length class per cutting (RNC), the mean single root length (SRL), the total root length per inserted cutting (TRL) and the percentage of unrooted cuttings (URC) were calculated as follows:

Total root number per inserted cutting (TRN):

$$
T R N=\sum n_{i} / 10
$$

Root number per length class per cutting (RNC):

$$
R N C=\sum\left(n_{L x}\right)_{i} / 10
$$

Single root length (SRL, $\mathrm{mm}$ ):

$$
S R L=\sum\left[\sum\left(n_{L x} L_{x}\right)\right]_{i} / \sum n_{i} * 10
$$

Total root length per cutting (TRL, cm):

$$
T R L=T R N \times S R L / 10
$$

Percentage of unrooted cuttings (URC, \%):

$$
U R C=n_{Z} x 100 / 10
$$

where $n$ stands for the number of roots of each inserted cutting, $i$ is each of 10 cuttings inserted per replication plot, $L_{x}$ is the mean length of the length interval (e.g. $1.5 \mathrm{~cm}$ for a length range of $1.0-2.0 \mathrm{~cm}$ ), $n_{L x}$ is the number of roots in the specific length interval, and $n_{z}$ is the number of unrooted cuttings out of 10 cuttings per replication.

\section{Histological examination of rooting zone}

Basal stem tissue of cuttings $(5 \mathrm{~mm})$ was collected during AR formation at 72 hpin (=72 hpe) and 168 hpin $(=168$ hpe) from two nitrogen treatments (nitrogen absorption level N-low at $2570 \mu \mathrm{mol} \mathrm{N} \mathrm{N}_{\mathrm{t}}$ and N-high at $3625 \mu \mathrm{mol} \mathrm{N} \mathrm{N}_{\mathrm{t}}$ ). Sample preparation and histological analysis was essentially accomplished as described in detail by Haensch [76]. In brief, basal segments were embedded in hydroxyethylmethacrylate (Histo-Technique-Set Technovit 7100; Kulzer, Wehrheim, Germany), cut into $6 \mu \mathrm{m}$ sections and stained with $0.05 \%$ toluidine blue O (Serva, Heidelberg, Germany). Microscopic analysis was carried out using an AxioImager A1 microscope in combination with an AxioCam MRc5 camera (Carl Zeiss, Jena, Germany) and the software AxioVision Rel. 4.7.1. Original images were supplemented with embedded annotations and a scale bar.

\section{Biochemical measurements and analyses}

Total nitrogen and fractionated pools of nitrogen (entire shoot tip) To analyse total nitrogen $\left(\mathrm{N}_{\mathrm{t}}\right)$, four fractionated pools of nitrogen (NF-pools: soluble: amide-N, nitrate- $\mathrm{N}$, amino-N and insoluble protein-N), with 10-15 cuttings were sampled per replication plot and gently dried at $60{ }^{\circ} \mathrm{C}$ for $48 \mathrm{~h}$. An adapted Kjeldahl method [77] was used to digest $300 \mathrm{mg}$ of a dried and pulverised subsample (1 g Wieninger's reagent (w/w 96,5 \% $\mathrm{Na}_{2} \mathrm{SO}_{4} ; 1,5 \%$ $\left.\mathrm{CuSO}_{4} ; 2 \% \mathrm{Se}\right)+2 \mathrm{~g} \mathrm{~K}_{2} \mathrm{SO}_{4}+10 \mathrm{ml} 98 \% \mathrm{H}_{2} \mathrm{SO}_{4}$ ) and to determine total nitrogen $\left(\mathrm{N}_{\mathrm{t}}\right)$ via water steam distillation (Büchi Kjeldahl Line: K-435, B-324, Titrino 719S; Büchi \& Metrohm, Switzerland). Another subsample of $500 \mathrm{mg}$ was extracted in $50 \mathrm{ml}$ of $1 \% \mathrm{w} / \mathrm{v} \mathrm{KAl}\left(\mathrm{SO}_{4}\right)_{2}$ for $30 \mathrm{~min}$ (Shaker $\mathrm{KL}$ 2, Edmund Bühler GmbH, Germany) and passed through a folded filter (Schleicher\&Schüll 595 1/2). To determine the nitrogen in each NF-pool, extract aliquots of every $10 \mathrm{ml}$ were used for the three distillations: (i) purely for amide- $\mathrm{N}$, (ii) after nitrate reduction by Devarda's alloy (w/w $45 \% \mathrm{Al}, 50 \% \mathrm{Cu}, 5 \% \mathrm{Zn}$ ), and (iii) after digestion of amino-N as with $\mathrm{N}_{\mathrm{t}}$. Finally, (iv) insoluble protein- $\mathrm{N}$ was analysed within the filter cake and the filter paper (Digestion: $2 \mathrm{~g}$ Wieninger's reagent $+4 \mathrm{~g} \mathrm{~K}_{2} \mathrm{SO}_{4}+20 \mathrm{ml} 98 \%$ $\mathrm{H}_{2} \mathrm{SO}_{4}$ ). The N-content of each NF-pool, the sum of NF- 
pools and the total nitrogen $\left(\mathrm{N}_{\mathrm{t}}\right)$ were calculated as $\mu \mathrm{mol} \mathrm{N}$ $\mathrm{g}^{-1}$ dry mass $(\mathrm{DM})$. The nitrogen recovery rate with the sum of NF-pools was accepted while the independently determined value for $\mathrm{N}_{\mathrm{t}}$ coincided in a range of $100 \pm 5 \%$.

Soluble protein (leaf and stem base) For soluble protein analyses during AR formation, two cuttings were collected per replication plot at the defined time points. From the fully developed, second oldest leaf of both cuttings, every two discs were excised and combined as one leaf sample $(2 \times 2$ discs, $\varnothing 4 \mathrm{~mm}, 45 \pm 12 \mathrm{mg} \mathrm{FM})$, while left and right lamina tissues were sampled equidistantly from the mid-vein and leaf borders. The basal stem segments of the two cuttings were combined as one stem sample $(2 \times 5 \mathrm{~mm}, 114 \pm 31 \mathrm{mg} F M)$. All samples were frozen immediately in liquid nitrogen and stored at $-80{ }^{\circ} \mathrm{C}$, homogenised in a cryogenic ball mill (Retsch MM 301, Haan, Germany) and extracted in $1 \mathrm{ml}$ buffer containing $50 \mathrm{mM}$ Tris- $\mathrm{HCl}, \mathrm{pH}$ 6.8, $5 \mathrm{mM} \mathrm{MgCl}_{2}$, $5 \mathrm{mM}$ Mercaptoethanol, $15 \%$ glycerine, $1 \mathrm{mM}$ EDTA, $1 \mathrm{mM}$ EGTA, $0.1 \mathrm{mM}$ Pefabloc. Extract aliquots of $0.1 \mathrm{ml}$ were mixed with $1 \mathrm{ml}$ Bradford reagent (SigmaAldrich Chemie $\mathrm{GmbH}$, Munich, Germany) and soluble protein [78] was quantified at $595 \mathrm{~nm}$ via spectrophotometer (Spekol 11, Carl Zeiss, Jena, Germany). Concentration of protein was calculated with an authentic standard (BSA - Albumin from bovine serum, SigmaAldrich, Germany) and expressed in $\mu \mathrm{g} \mathrm{g}^{-1} \mathrm{FM}$.

Free proteinogenic amino acids (leaf and stem base) For free amino acid analyses in leaf and stem base tissue, every five (Exp. $3 A A-N D$, details of design see ahead or in additional files) or two (Exp. $5 A A-D C R$ ) cuttings were collected per replication plot and at defined time points. Two leaf discs were excised $(1 \times 2$ discs, at left and right sides of the mid-vein, $\varnothing 4 \mathrm{~mm}, 25 \pm 5 \mathrm{mg} \mathrm{FM}$ ) with the fully developed, second oldest leaf of each cutting while five (Exp. 3 $A A-N D)$ or two (Exp. $3 A A-D C R)$ replicated leaf samples were obtained. The basal stem segment of each cutting $(1 \times 5 \mathrm{~mm}, 50 \pm 15 \mathrm{mg} \mathrm{FM})$ contributed five or two replicated stem samples, respectively. Samples were frozen immediately in liquid nitrogen and stored at $-80{ }^{\circ} \mathrm{C}$. A homogenization of each sample in a cryogenic ball mill (Retsch MM 301, Haan, Germany) preceded the extraction with $500 \mu \mathrm{l} 80 \%$ ethanol in a thermostat shaker $\left(80{ }^{\circ} \mathrm{C}\right.$, $45 \mathrm{~min}$ ) (Thermomixer Comfort, Eppendorf, Germany). After 15 min cooling, samples were centrifuged for $5 \mathrm{~min}$ at $14,000 \mathrm{rpm}$ and $4{ }^{\circ} \mathrm{C}$. The supernatant was transferred into a new tube and evaporated in a vacuum concentrator (Savant SpeedVac, SPD111V, Thermo Fisher Scientific, Germany) at $50{ }^{\circ} \mathrm{C}$ to dryness (60-90 min). The dry residue was resolved in $150 \mu \mathrm{l}(\operatorname{Exp} .3 A A-N D)$ or $250 \mu \mathrm{l}$ (Exp. $5 A A-D C R$ ) and either frozen at $-20{ }^{\circ} \mathrm{C}$ until analysis or directly centrifuged for $1 \mathrm{~min}$ at
14,000 rpm. An aliquot was derivatised with 6aminoquinolyl-N-hydroxysuccinimidyl carbamate (AQC) according to Ahkami et al. 2009 [8]. Individual contents of 18 amino acids and the nitrogen portion they reserved were calculated as nmol g-1 FM and as nmol $\mathrm{N}_{\mathrm{t}} \mathrm{g}^{-1} \mathrm{FM}$. Total free amino acids (AA) and their related total nitrogen contents (AA- $\mathrm{N}_{t}$ ) were specified in $\mu \mathrm{mol} \mathrm{g} \mathrm{g}^{-1} \mathrm{FM}$ and in nmol AA- $\mathrm{N}_{\mathrm{t}} \mathrm{g}^{-1} \mathrm{FM}$, respectively.

Statistical analyses Nitrogen absorption $\left(\mathrm{N}_{\mathrm{t}}\right)$ and pools of nitrogen (NF-pools), adventitious root (AR) formation, early cytological events (CYT), free amino acids (AA) and soluble proteins (PR) were studied in response to distinct or combined environmental factors like donor plant nitrogen fertigation $\left(\mathrm{N}_{\mathrm{d}}\right)$, and time post excision of cuttings with exposure to dark (D) and post insertion during cultivation of cuttings at diurnal light (CR) totally in ten experiments. In these experiments factorial designs were applied which are specified in Additional files 1, 2 and 3 and assigned to results in Figs. 1, 2, 3, 4, 5, 6 and 7 (Exp: 1 NF-N, $2 A R-N D$, $3 A A-N D, 4 A R-D, 5 A A-D C R, 6 N F-N D, 7 A R-N \pm C Y T, 8$ $P R-N D C R, 9 N F-N D C R)$. The analyses were accomplished by ANOVA/MANOVA in the data analysis software system STATISTICA [79]. Linear correlation and regression analyses between total nitrogen $\left(\mathrm{N}_{\mathrm{t}}\right)$ and $\mathrm{N}_{\mathrm{t}}$ allocation to the NF-pools as well as between $\mathrm{N}_{t}$ and the rooting of the cuttings were performed in the Basic Statistics module. Differences among mean values were assessed with Tukey's honestly significant difference (HSD) test $(\alpha=0.05)$, and correlation coefficients were considered significant at $\mathrm{P} \leq$ 0.05. In individual figures, vertical bars depict $95 \%$ confidence intervals of least square mean (LSM) values as uniform standard measure of dispersion of a current interaction effect. Thereby calculations of $95 \%$ confidence intervals of LSM values were accepted as default software mode. In appropriate cases calculations of $95 \%$ confidence intervals of weighted mean values where conducted to show variably deviations in dispersion of single mean values in the current interaction effect. Different lowercase letters on data points denote significant differences at $P \leq 0.05$.

\section{Additional files}

Additional file 1: Experiments 1-9 of nitrogen preconditioning of cuttings. (PDF $22 \mathrm{~kb}$ )

Additional file 2: Explanation of experimental designs for statistical analyses. (PDF $13 \mathrm{~kb}$ )

Additional file 3: Supplemental data of Figures 2 to 7. (PDF $31 \mathrm{~kb}$ )

\section{Abbreviations}

AA: Free amino acids; AR: Adventitious root; arg: Arginine; AS: Asparagine synthetase genes; asn: Asparagine; asp: Aspartate; CK: Cytokinin; CYT: Cytological events; GA: Gibberellins; gln: Glutamine; glu: Glutamate; hde: Hours of dark exposition; hpe: Hours post excision; hpin: Hours post insertion (i.e. in perlite substrate for AR formation under diurnal light); IAA: Indol-3-Acetic-Acid; ND: N deficiency; $N_{d}$ level: Nitrogen supply level to 
donor plants; NF-pools: Fractionated pools of nitrogen; NO: Nitric oxide; $\mathrm{N}_{\mathrm{t}}$ : Total nitrogen; PAT: Polar auxin transport; PIN: Auxin transport protein PIN-FORMED; PR: Soluble proteins; RNC: Root number per length class per cutting; SRL: Single root length; TRL: Total root length per inserted cutting; TRN: Total root number per cutting

\section{Acknowledgements}

We thank Sabine Czekalla, Barbara Weinlich and Katrin Schultz (all IGZ) for their excellent technical assistance in growing the donor plants and cuttings, sampling and adeptly chemical and histological analyses.

\section{Funding}

This work was funded by the German Research Foundation (DFG, DR411/2-1) and supported by the states of Saxony-Anhalt and Brandenburg, the Free State of Thuringia and the Federal Republic of Germany.

\section{Availability of data and materials}

All data supporting our conclusions is contained within the manuscript and the Additional files.

\section{Authors' contributions}

SZ, KTH and UD designed and performed the research. SZ and KTH analyzed the data. SZ wrote the manuscript with histological contributions of KTH and with contributions of MRH to the development of the model. UD and MRH edited the manuscript. All authors read and approved the final manuscript.

\section{Competing interests}

The authors declare that they have no competing interests.

\section{Consent for publication}

Not applicable.

\section{Ethics approval and consent to participate} Not applicable.

\section{Author details}

'Department of Plant Nutrition, Leibniz Institute of Vegetable \& Ornamental Crops (IGZ), Kuehnhaeuser Str. 101, 99090 Erfurt, Germany. ${ }^{2}$ Department of Plant Propagation, Leibniz Institute of Vegetable \& Ornamental Crops (IGZ), Kuehnhaeuser Str. 101, 99090 Erfurt, Germany. ${ }^{3}$ Leibniz Institute of Plant Genetics and Crop Plant Research (IPK), Molecular Plant Nutrition, Corrensstr. 3, 06466 Gatersleben, Germany.

Received: 13 June 2016 Accepted: 16 September 2016 Published online: 10 October 2016

\section{References}

1. Foyer $\mathrm{CH}$. Markers and signals associated with nitrogen assimilation in higher plants. J Exp Bot. 2003;54(382):585-93.

2. Sulpice R, Nikoloski Z, Tschoep H, Antonio C, Kleessen S, Larhlimi A, Selbig J, Ishihara H, Gibon Y, Fernie AR, et al. Impact of the Carbon and Nitrogen Supply on Relationships and Connectivity between Metabolism and Biomass in a Broad Panel of Arabidopsis Accessions(1 W OA). Plant Physiol. 2013;162(1):347-63.

3. Liu R, Chen S, Jiang J, Zhu L, Zheng C, Han S, Gu J, Sun J, Li H, Wang H, et al. Proteomic changes in the base of chrysanthemum cuttings during adventitious root formation. BMC Genomics. 2013;14:919.

4. da Costa CT, de Almeida MR, Ruedell CM, Schwambach J, Maraschin FS, FettNeto AG. When stress and development go hand in hand: main hormonal controls of adventitious rooting in cuttings. Front Plant Sci. 2013:4:133.

5. Bellini C, Pacurar DI, Perrone I. Adventitious roots and lateral roots: similarities and differences. Annu Rev Plant Biol. 2014;65(1):639-66.

6. Negi S, Sukumar P, Liu X, Cohen JD, Muday GK. Genetic dissection of the role of ethylene in regulating auxin-dependent lateral and adventitious root formation in tomato. Plant J. 2010;61(1):3-15.

7. Lavenus J, Goh T, Roberts I, Guyomarc'h S, Lucas M, De Smet I, Fukaki H, Beeckman T, Bennett M, Laplaze L. Lateral root development in Arabidopsis: fifty shades of auxin. Trends Plant Sci. 2013;18(8):455-63.

8. Ahkami AH, Lischewski S, Haensch K-T, Porfirova S, Hofmann J, Rolletschek H, Melzer M, Franken P, Hause B, Druege U, et al. Molecular physiology of adventitious root formation inPetunia hybridacuttings: involvement of wound response and primary metabolism. New Phytol. 2009;181(3):613-25.
9. Ahkami A, Scholz U, Steuernagel B, Strickert M, Haensch KT, Druege U, Reinhardt D, Nouri E, von Wiren N, Franken P, et al. Comprehensive Transcriptome Analysis Unravels the Existence of Crucial Genes Regulating Primary Metabolism during Adventitious Root Formation in Petunia hybrida. PLoS One. 2014;9(6):e100997.

10. Druege U, Franken P, Hajirezaei MR. Plant hormone homeostasis, signaling, and function during adventitious root formation in cuttings. Front Plant Sci. 2016;7:381.

11. Blakesley D, Weston GD, Hall JF. The role of endogenous auxin in root initiation Part I: Evidence from studies on auxin application, and analysis of endogenous levels. Plant Growth Regul. 1991;10:341-53.

12. Pagnussat GC. Nitric Oxide and Cyclic GMP Are Messengers in the Indole Acetic Acid-Induced Adventitious Rooting Process. Plant Physiol. 2003;132(3):1241-8.

13. Flores T, Todd CD, Tovar-Mendez A, Dhanoa PK, Correa-Aragunde N, Hoyos ME, Brownfield DM, Mullen RT, Lamattina L, Polacco JC. Arginase-Negative Mutants of Arabidopsis Exhibit Increased Nitric Oxide Signaling in Root Development. Plant Physiol. 2008;147(4):1936-46.

14. Zheng Z, Guo Y, Novák O, Dai X, Zhao Y, Ljung K, Noel JP, Chory J. Coordination of auxin and ethylene biosynthesis by the aminotransferase VAS1. Nat Chem Biol. 2013;9(4):244-6.

15. Bogre L, Henriques R, Magyar Z. TOR tour to auxin. EMBO J. 2013;32(8): 1069-71.

16. Ahkami AH, Melzer M, Ghaffari MR, Pollmann S, Ghorbani Javid M, Shahinnia F, Hajirezaei MR, Druege U. Distribution of indole-3-acetic acid in Petunia hybrida shoot tip cuttings and relationship between auxin transport, carbohydrate metabolism and adventitious root formation. Planta. 2013;238: 499-517.

17. Druege U, Zerche S, Kadner R. Nitrogen- and Storage-affected Carbohydrate Partitioning in High-light-adapted Pelargonium Cuttings in Relation to Survival and Adventitious Root Formation under Low Light. Ann Bot. 2004:94(6):831-42.

18. Rapaka VK, Bessler B, Schreiner M, Druege U. Interplay between initial carbohydrate availability, current photosynthesis, and adventitious root formation in Pelargonium cuttings. Plant Sci. 2005;168(6):1547-60.

19. Liu F, Guo FQ. Nitric Oxide Deficiency Accelerates Chlorophyll Breakdown and Stability Loss of Thylakoid Membranes during Dark-Induced Leaf Senescence in Arabidopsis. PLOS ONE. 2013:8(2):e56345.

20. Pellicer V, Guehl JM, Daudet FA, Cazet M, Riviere LM, Maillard P. Carbon and nitrogen mobilization in Larix $\times$ eurolepis leafy stem cuttings assessed by dual $13 C$ and 15N labeling: relationships with rooting. Tree Physiology. 2000;20:807-14.

21. Suzuki T, Kohno K. Changes in Nitrogen levels and free amino acids in rooting cuttings of mulberry (Morus alba). Physiol Plant. 1983;59(3):455-60.

22. Schluter U, Mascher M, Colmsee C, Scholz U, Brautigam A, Fahnenstich H, Sonnewald U. Maize source leaf adaptation to nitrogen deficiency affects not only nitrogen and carbon metabolism but also control of phosphate homeostasis. Plant Physiol. 2012;160(3):1384-406.

23. Aguera $E$, Cabello $P$, de la Haba $P$. Induction of leaf senescence by low nitrogen nutrition in sunflower (Helianthus annuus) plants. Physiol Plant. 2010;138(3):256-67.

24. Giehl RF, Gruber BD, von Wiren N. It's time to make changes: modulation of root system architecture by nutrient signals. J Exp Bot. 2014:65(3):769-78.

25. Mohd-Radzman NA, Djordjevic MA, Imin N. Nitrogen modulation of legume root architecture signaling pathways involves phytohormones and small regulatory molecules. Front Plant Sci. 2013;4:385

26. Druege $U$, Zerche $S$, Kadner R, Ernst M. Relation between nitrogen status, carbohydrate distribution and subsequent rooting of chrysanthemum cuttings as affected by pre-harvest nitrogen supply and cold-storage. Ann Bot. 2000;85(5):687-701.

27. Zerche S, Druege U. Nitrogen content determines adventitious rooting in Euphorbia pulcherrima under adequate light independently of pre-rooting carbohydrate depletion of cuttings. Sci Hortic. 2009;121(3):340-7.

28. Scagel CF. Changes in cutting composition during early stages of adventitious rooting of miniature rose altered by inoculation with arbuscular mycorrhizal fungi. J Am Soc Hortic Sci. 2004;129(5):624-34.

29. Klopotek Y, Haensch K-T, Hause B, Hajirezaei M-R, Druege U. Dark exposure of petunia cuttings strongly improves adventitious root formation and enhances carbohydrate availability during rooting in the light. J Plant Physiol. 2010;167(7):547-54.

30. Marschner $\mathrm{H}$. Role of phytohormones in the regulation of the sink-source relationships. In: Petra M, editor. Marschner's mineral nutrition of higher plants. 3rd ed. London: Academic; 2012. p. 120-31.

31. Druege U, Franken $\mathrm{P}$, Lischewski S, Ahkami AH, Zerche S, Hause B, Hajirezaei $\mathrm{M}-\mathrm{R}$. Transcriptomic analysis reveals ethylene as stimulator and auxin as regulator of adventitious root formation in petunia cuttings. Front Plant Sci. 2014;5:494. doi:10.3389/fpls.2014.00494. 
32. Sakakibara H, Takei $\mathrm{K}$, Hirose N. Interactions between nitrogen and cytokinin in the regulation of metabolism and development. Trends Plant Sci. 2006; 11(9):440-8.

33. Kamada-Nobusada T, Makita N, Kojima M, Sakakibara H. Nitrogendependent regulation of de novo cytokinin biosynthesis in rice: the role of glutamine metabolism as an additional signal. Plant Cell Physiol. 2013;54(11):1881-93.

34. Agullo-Anton MA, Ferrandez-Ayela A, Fernandez-Garcia N, Nicolas C, Albacete A, Perez-Alfocea F, Sanchez-Bravo J, Perez-Perez JM, Acosta M. Early steps of adventitious rooting: morphology, hormonal profiling and carbohydrate turnover in carnation stem cuttings. Physiol Plant. 2014;150(3):446-62.

35. Perilli S, Moubayidin L, Sabatini S. The molecular basis of cytokinin function. Curr Opin Plant Biol. 2010;13(1):21-6.

36. Della Rovere F, Fattorini L, D'Angeli S, Veloccia A, Falasca G, Altamura MM. Auxin and cytokinin control formation of the quiescent centre in the adventitious root apex of arabidopsis. Ann Bot. 2013;112(7):1395-407.

37. Marschner $\mathrm{H}$. Effect of Nutrition on the endogenous concentration of phytohormons. In: Petra M, editor. Marschner's Mineral Nutrition of Higher Plants. 3rd ed. London: Academic; 2012. p. 127-9.

38. Bhalerao RP, EkloÈ J, Ljung K, Marchant A, Bennett M, Sandberg GÈ r. Shootderived auxin is essential for early lateral root emergence in Arabidopsis seedlings. Plant J. 2002;29(3):325-32.

39. Santos KM, Fisher PR, Yeager TH, Simonne EH, Carter HS, Argo WR. Effect of Petunia Stock Plant Nutritional Status on Fertilizer Response during Propagation. J Plant Nutr. 2011;34:1424-36.

40. Klopotek Y, Franken P, Klaering H-P, Fischer K, Hause B, Hajirezaei M-R, Druege $U$. A higher sink competitiveness of the rooting zone and invertases are involved in dark stimulation of adventitious root formation in Petunia hybrida cuttings. Plant Sci. 2016;243:10-22.

41. Santos KM, Fisher PR, Argo WR. Survey of tissue nutrient levels in vegetative cuttings. Commun Soil Sci Plant Anal. 2011;42(6):669-93.

42. Zerche S, Drüge U, Kadner R. Nitrat zeigt innere Qualität - Status und Bewurzelung von Chrysanthemen-Stecklingen. Gärtnerbörse. 2001;101(2):16-9.

43. Svenson SED, Jr FT. Change in tissue elemental concentration during root initiation and development of poinsettia cuttings. HortScience. 1995;30(3):617-9.

44. Brouquisse R, Jean-Pierre G, Raymond P. Induction of a carbon-starvationrelated proteolysis in whole maize plants submitted to light/dark cycles and to extended darkness. Plant Physiol. 1998;117:1281-91.

45. Lillo C, Meyer C, Lea US, Provan F, Oltedal S. Mechanism and importance of post-translational regulation of nitrate reductase. J Exp Bot. 2004;55(401): 1275-82.

46. Scheible WR, Morcuende R, Czechowski T, Fritz C, Osuna D, Palacios-Rojas N, Schindelasch D, Thimm O, Udvardi MK, Stitt M. Genome-wide reprogramming of primary and secondary metabolism, protein synthesis, cellular growth processes, and the regulatory infrastructure of Arabidopsis in response to nitrogen. Plant Physiol. 2004;136(1):2483-99.

47. Forde BG, Lea PJ. Glutamate in plants: metabolism, regulation, and signalling. J Exp Bot. 2007:58(9):2339-58.

48. Wang L, Jiang J, Song A, Wang H, Li P, Guan Z, Chen F, Chen S. Comparative transcriptome analysis of Chrysanthemum nankingense in response to nitrogen deficiency. Sci Hortic. 2015;195:101-7.

49. Welander T. Influence of Nitrogen and Sucrose in the Medium and of Irradiance of the Stock Plants on Root Formation in Pelargonium Petioles. Physiol Plant. 1978;43(2):136-41.

50. Simonovic AD, Anderson MD. Analysis of methionine oxides and nitrogentransporting amono acids and acclimated maize seedlings*. Amino Acids. 2007:33:607-6013

51. Kant S, Bi YM, Rothstein SJ. Understanding plant response to nitrogen limitation for the improvement of crop nitrogen use efficiency. J Exp Bot. 2011;62(4):1499-509.

52. Delrot $S$, Atanassova R, Maurousset $L$. Regulation of sugar, amino acid and peptide plant membrane transporters. Biochim Biophys Acta. 2000;1465:281-306.

53. Weckenmann D, Martin P. Endopeptidase activity and nitrogen mobilization in senescing leaves of Nicotiana rustica in light and dark. Physiol Plant. 1984;60(3):333-40.

54. Lea PJ, Sodek L, Parry MAJ, Shewry PR, Halford NG. Asparagine in plants. Ann Appl Biol. 2007;150(1):1-26.

55. Foyer CHE, Hanma Z. Nitrogen Metabolism in Plants in the Post-Genomic Era. Annual Plant Reviews. 2010;42(Wiley-Blackwell (an imprint of John Wiley \& Sons Ltd)):366.
56. Beato VM, Rexach J, Navarro-Gochicoa MT, Camacho-Cristobal JJ, Herrera-Rodriguez MB, Maldonado JM, Gonzalez-Fontes A. A tobacco asparagine synthetase gene responds to carbon and nitrogen status and its root expression is affected under boron stress. Plant Sci. 2010; 178(3):289-98.

57. Masclaux-Daubresse C, Daniel-Vedele F, Dechorgnat J, Chardon F, Gaufichon L, Suzuki A. Nitrogen uptake, assimilation and remobilization in plants: challenges for sustainable and productive agriculture. Ann Bot. 2010;105(7):1141-57.

58. Schluter U, Colmsee C, Scholz U, Brautigam A, Weber APM, Zellerhoff N, Bucher M, Fahnenstich $\mathrm{H}$, Sonnewald U. Adaptation of maize source leaf metabolism to stress related disturbances in carbon, nitrogen and phosphorus balance. BMC Genomics. 2013;14:442.

59. Rubio-Wilhelmi MM, Sanchez-Rodriguez E, Rosales MA, Blasco B, Rios JJ, Romero L, Blumwald E, Ruiz JM. Ammonium formation and assimilation in PSARK: : IPT tobacco transgenic plants under low N. J Plant Physiol. 2012; 169(2):157-62

60. Dietrich K, Weltmeier F, Ehlert A, Weiste C, Stahl M, Harter K, Droge-Laser W. Heterodimers of the Arabidopsis Transcription Factors bZIP1 and bZIP53 Reprogram Amino Acid Metabolism during Low Energy Stress. Plant Cell Online. 2011;23(1):381-95.

61. Usadel B, Blasing OE, Gibon Y, Retzlaff K, Hohne M, Gunther M, Stitt M. Global transcript levels respond to small changes of the carbon status during progressive exhaustion of carbohydrates in Arabidopsis rosettes. Plant Physiol. 2008;146(4):1834-61.

62. Bieker S, Zentgraf U: Plant Senescence and Nitrogen Mobilization and Signaling. Senescence and Senescence-Related Disorders. In: Wang Zhiwei (Ed). 2013. p. 53-83. ISBN: 978-953-51-0997-6, InTech. doi: 105772/54392 (Available from: http://dx.doi.org/10.5772/54392).

63. Potel F, Valadier MH, Ferrario-Mery S, Grandjean O, Morin H, Gaufichon L, Boutet-Mercey S, Lothier J, Rothstein SJ, Hirose N, et al. Assimilation of excess ammonium into amino acids and nitrogen translocation in Arabidopsis thaliana- roles of glutamate synthases and carbamoylphosphate synthetase in leaves. FEBS J. 2009;276(15):4061-76.

64. Slocum RD. Genes, enzymes and regulation of arginine biosynthesis in plants. Plant Physiol Biochem. 2005;43(8):729-45.

65. Miyashita $Y$, Good AG. NAD(H)-dependent glutamate dehydrogenase is essential for the survival of Arabidopsis thaliana during dark-induced carbon starvation. J Exp Bot. 2008;59(3):667-80.

66. Lam HM, Hsieh MH, Coruzzi G. Reciprocal regulation of distinct asparagine synthetase genes by light and metabolites in Arabidopsis thaliana. Plant J. 1998;16(3):345-53.

67. Buchanan-Wollaston $V$, Page T, Harrison E, Breeze E, Lim PO, Nam HG, Lin JF, Wu S-H, Swidzinski J, Ishizaki K, et al. Comparative transcriptome analysis reveals significant differences in gene expression and signalling pathways between developmental and dark/starvation-induced senescence in Arabidopsis. Plant J. 2005;42(4):567-85.

68. Tome F, Nagele T, Adamo M, Garg A, Marco-Llorca C, Nukarinen E, Pedrotti $L$, Peviani A, Simeunovic A, Tatkiewicz A, et al. The low energy signaling network. Front Plant Sci. 2014;5(Article 353):1-12.

69. Feller U, Anders I, Mae T. Rubiscolytics: fate of Rubisco after its enzymatic function in a cell is terminated. J Exp Bot. 2008;59(7):1615-24.

70. Martinez DE, Costa ML, Gomez FM, Otegui MS, Guiamet JJ. 'Senescenceassociated vacuoles' are involved in the degradation of chloroplast proteins in tobacco leaves. Plant J. 2008;56(2):196-206.

71. Woodward AW, Bartel B. Auxin: Regulation, action, and interaction. Ann Bot. 2005;95(5):707-35

72. Marrocco K, Bergdoll M, Achard P, Criqui MC, Genschik P. Selective proteolysis sets the tempo of the cell cycle. Curr Opin Plant Biol. 2010;13(6):631-9.

73. Nodzon LA, Xu WH, Wang YS, Pi LY, Chakrabarty PK, Song WY. The ubiquitin ligase XBAT32 regulates lateral root development in Arabidopsis. Plant J. 2004:40(6):996-1006.

74. Wang HD, Makeen K, Yan Y, Cao Y, Sun SB, Xu GH. OsSIZ1 Regulates the Vegetative Growth and Reproductive Development in Rice. Plant Mol Biol Rep. 2011;29(2):411-7.

75. Lohr D, Tillmann P, Zerche S, Druege U, Rath T, Meinken E. Non-destructive measurement of nitrogen status of leafy ornamental cuttings by near infrared reflectance spectroscopy (NIRS) for assessment of rooting capacity. Biosystems Engineering. 2016;148:157-67.

76. Haensch KT. Morpho-histological study of somatic embryo-like structures in hypocotyls cultures of Pelargonium × hortorum Bailey. Plant Cell Rep. 2004; 22:376-81. 
77. Jakob F, Vielemeyer HP, Podlesak W. Studies in the Suitability of Nitrogen Fractions for Diagnosing the Nitrogen Status of Winter-Wheat (TriticumAestivum L). Archiv fuer Acker und Pflanzenbau und Bodenkunde - Arch Agron Soil Sci. 1986:30(10):599-605.

78. Bradford MM. A rapid and sensitive method for the quantification of microgram quantities of protein utilizing the principle of protein-dye-binding. Anal Biochem. 1976;72:248-54.

79. StatSoft: STATISTICA for Windows (data analysis software system), Version 6, (www.statsoft.com). Internet 2004

Submit your next manuscript to BioMed Central and we will help you at every step:

- We accept pre-submission inquiries

- Our selector tool helps you to find the most relevant journal

- We provide round the clock customer support

- Convenient online submission

- Thorough peer review

- Inclusion in PubMed and all major indexing services

- Maximum visibility for your research

Submit your manuscript at www.biomedcentral.com/submit
Biomed Central 